\title{
Protein Kinase M Maintains Long-Term Sensitization and Long-Term Facilitation in Aplysia
}

\author{
Diancai Cai, ${ }^{1 \star}$ Kaycey Pearce, ${ }^{1 \star}$ Shanping Chen, ${ }^{1}$ and David L. Glanzman ${ }^{1,2}$ \\ ${ }^{1}$ Department of Integrative Biology and Physiology, University of California, Los Angeles, College, Los Angeles, California 90095-1606, and ${ }^{2}$ Department of \\ Neurobiology and Brain Research Institute, David Geffen School of Medicine, University of California, Los Angeles, Los Angeles, California 90095-1761
}

How the brain maintains long-term memories is one of the major outstanding questions in modern neuroscience. Evidence from mammalian studies indicates that activity of a protein kinase $\mathrm{C}(\mathrm{PKC})$ isoform, protein kinase $\mathrm{M} \zeta(\mathrm{PKM} \zeta)$, plays a critical role in the maintenance of long-term memory. But the range of memories whose persistence depends on PKM $\zeta$, and the mechanisms that underlie the effect of PKM $\zeta$ on long-term memory, remain obscure. Recently, a PKM isoform, known as PKM Apl III, was cloned from the nervous system of Aplysia. Here, we tested whether PKM Apl III plays a critical role in long-term memory maintenance in Aplysia. Intrahemocoel injections of the pseudosubstrate inhibitory peptide ZIP ( $\zeta$ inhibitory peptide) or the PKC inhibitor chelerythrine erased the memory for long-term sensitization (LTS) of the siphon-withdrawal reflex (SWR) as late as $7 \mathrm{~d}$ after training. In addition, both PKM inhibitors disrupted the maintenance of long-term ( $\geq 24 \mathrm{~h}$ ) facilitation (LTF) of the sensorimotor synapse, a form of synaptic plasticity previously shown to mediate LTS of the SWR. Together with previous results (Bougie et al., 2009), our results support the idea that long-term memory in Aplysia is maintained via a positive-feedback loop involving PKM Apl III-dependent protein phosphorylation. The present data extend the known role of PKM in memory maintenance to a simple and well studied type of long-term learning. Furthermore, the demonstration that PKM activity underlies the persistence of LTF of the Aplysia sensorimotor synapse, a form of synaptic plasticity amenable to rigorous cellular and molecular analyses, should facilitate efforts to understand how PKM activity maintains memory.

\section{Introduction}

Traditionally, memories have been believed to undergo a single, time-dependent process of consolidation during the transition from short-term to long-term (Müller and Pilzecker, 1900; McGaugh, 2000). Early in this process, memories are labile and subject to disruption by such treatments as application of an electroconvulsive shock (McGaugh, 1966) and inhibition of protein synthesis (Agranoff and Klinger, 1964); once consolidated, however, memories are thought to be relatively permanent and resistant to disruption by amnestic treatments. However, the standard model of memory consolidation has been challenged by evidence indicating that the persistence of memory depends on some active, ongoing process, and that even well established memories can become rapidly degraded if this process is interrupted (Drier et al., 2002; Ling et al., 2002; Pastalkova et al., 2006; Shema et al., 2007).

In Aplysia, the induction of serotonin (5-HT)-induced longterm facilitation (LTF) of sensorimotor synapses, the form of synaptic plasticity that underlies long-term sensitization (LTS)

\footnotetext{
Received Sept. 9, 2010; revised Feb. 22, 2011; accepted March 3, 2011.

Author contributions: D.C. and D.L.G. designed research; D.C., K.P., and S.C. performed research; D.C. and S.C. analyzed data; D.L.G. wrote the paper.

This work was supported by National Institutes of Health Grant R37 NS029563 (D.L.G.). We thank R. Barakat, D. Li, L. Nguyen, and T. Phan for assistance with the behavioral training. We also thank F. Krasne, T. O'Dell, T. Sacktor, and W. Sossin for their helpful comments on a previous version of this manuscript.

${ }^{*}$ D.C. and K.P. contributed equally to this work.

Correspondence should be addressed to Dr. David L. Glanzman, Gonda (Goldschmied) Neuroscience and Genetics Research Center, 695 Charles E. Young Drive South, Box 951761, University of California, Los Angeles, Los Angeles, CA 90095-1761. E-mail: dglanzman@physci.ucla.edu.

DOI:10.1523/JNEUROSCI.4744-10.2011

Copyright $\odot 2011$ the authors $\quad 0270-6474 / 11 / 316421-11 \$ 15.00 / 0$
}

(Frost et al., 1985), requires cAMP response element-binding protein (CREB) (Dash et al., 1990; Bartsch et al., 1995). Activation of CREB has been hypothesized to initiate the processes of transcription and translation that mediate long-term memory in Aplysia (Goelet et al., 1986). Recently, it has been proposed that early maintenance, at least, of long-term memory in Aplysia is mediated by ongoing activity of cytoplasmic polyadenylation element binding protein (ApCPEB) (Si et al., 2003a,b). ApCPEB can undergo a change in its state from an inactive monomer, to an active multimer; in the latter state the protein is self-perpetuating (Si et al., 2010), a capacity that endows it, potentially, with the ability to subserve the persistence of memory. Although most of the work implicating CPEB in memory maintenance has been done in Aplysia, there is evidence that homologs of ApCPEB have a similar function in Drosophila (Keleman et al., 2007) and, possibly, in mammals (Alarcon et al., 2004).

An alternate molecular mechanism for memory maintenance has emerged from the work of Sacktor and colleagues. They have shown that a constitutively active fragment of the mammalian atypical protein kinase $\mathrm{C} \zeta(\mathrm{PKC} \zeta)$, protein kinase $\mathrm{M} \zeta(\mathrm{PKM} \zeta)$, plays a critical role in the persistence of long-term potentiation (LTP) in the mammalian hippocampus (Ling et al., 2002; Pastalkova et al., 2006), as well as several forms of mammalian memory (Pastalkova et al., 2006; Shema et al., 2007; Serrano et al., 2008). Until now, most of the studies examining the role of PKMtype isoforms in memory have been performed on rodents (but see Drier et al., 2002).

An atypical PKC has been cloned from the nervous system of Aplysia (Bougie et al., 2009). This Aplysia PKC, PKC Apl III, can 
undergo proteolytic cleavage by calpain, thereby yielding a PKM fragment, PKM Apl III. Furthermore, 5-HT appears to activate PKM Apl III in motor neurons of Aplysia (Villareal et al., 2009). The discovery and initial characterization of PKM Apl III have set the stage for the present examination of the role of PKM in memory retention in Aplysia.

\section{Materials and Methods}

Behavioral experiments. Adult Aplysia californica (80-120 g) were obtained from a local supplier (Alacrity Marine Biological). (Note that Aplysia are hermaphroditic organisms.) Animals were housed in a 190 liter aquarium filled with cooled $\left(12-14^{\circ} \mathrm{C}\right)$, aerated seawater (Catalina Water Company). The behavioral training and testing methods were similar to those previously described (Fulton et al., 2008). Three pretests were performed at once per $10 \mathrm{~min}$, beginning $25 \mathrm{~min}$ before the start of training. During each pretest, as well as in the posttraining tests, the siphon was lightly stimulated with a broom bristle, and the duration of the resulting siphon withdrawal reflex (SWR) was timed. Sensitization training consisted of five bouts of electrical shocks delivered to the tail at 20 min intervals. During each bout, the animal received three trains of shocks spaced $2 \mathrm{~s}$ apart. Each train was $1 \mathrm{~s}$ in duration; the shocks $(10 \mathrm{~ms}$ pulse duration, $40 \mathrm{~Hz}, 120 \mathrm{~V}$ ) were delivered via a Grass stimulator (S88; Astro-Med) connected to platinum wires implanted in the tail. After training, the animals were given posttests as indicated in the figures.

The myristoylated pseudosubstrate inhibitor, $\zeta$ inhibitory peptide (ZIP) (myr-SIYRRGARRWRKL-OH) (Invitrogen), was dissolved in $\mathrm{dH}_{2} \mathrm{O}$ (vehicle) to a concentration of $5 \mathrm{~mm}$. A scrambled peptide (myr-RLYRKRIWRSAGR-OH; ScrZIP) (Tocris), also dissolved in $\mathrm{dH}_{2} \mathrm{O}$ to a concentration of $5 \mathrm{~mm}$, or the vehicle alone, was used in control experiments. Chelerythrine (EMD Biosciences) was dissolved in $\mathrm{dH}_{2} \mathrm{O}$ to a concentration of $10 \mathrm{~mm}$. Injections of $200 \mu \mathrm{l}$ per $100 \mathrm{~g}$ of body weight of ZIP, ScrZIP, or chelerythrine were made into the animal's neck. Anisomycin was first dissolved in dimethyl sulfoxide (DMSO) to a concentration of $40 \mathrm{~mm}$, and then diluted in artificial seawater (ASW) to a concentration of $8 \mathrm{~mm}(20 \% \mathrm{DMSO})$. A volume of $500 \mu \mathrm{l}$ per $100 \mathrm{~g}$ of body weight of anisomycin was injected into the animals. Injections of the same amount of vehicle solution (DMSO in ASW) were made in control experiments. The final concentrations of ZIP/ScrZIP, chelerythrine, and anisomycin in the animal were $\sim 10,20$, and $40 \mu \mathrm{M}$, respectively. The final concentration of DMSO in the hemocoel was $\sim 0.1 \%$. The specific times at which the intrahemocoel injections were made are indicated in the relevant figures.

Biotinylated ZIP staining. To confirm that myristoylated ZIP can penetrate the connective tissue sheath surrounding the ganglia of the Aplysia CNS, and enter inside neurons, biotinylated myristoylated ZIP (von Kraus et al., 2010) was injected into animals at the same concentration (200 $\mu \mathrm{l}$ per $100 \mathrm{~g}$ body weight) as was used for myristoylated ZIP in the behavioral experiments. Five hours after the intrahemocoel injection of biotin-labeled ZIP, the pleural-pedal ganglia were removed from the animal and fixed with $4 \%$ paraformaldehyde in PBS with $30 \%$ sucrose overnight at $4^{\circ} \mathrm{C}$. The ganglia were then rinsed with fresh $\mathrm{PBS} / 30 \%$ sucrose and transferred to plastic molds, where they were embedded in optimal cutting temperature compound (Sakura Finetek) and frozen on dry ice. The frozen tissue block was cut into $20-\mu \mathrm{m}$-thick sections with a cryotome. The tissue sections were placed onto glass slide, rinsed three times (5 min per rinse) with PBS, and incubated with PBS containing $0.3 \%$ Triton for $10 \mathrm{~min}$. Slices were incubated with the Vectastain Elite $\mathrm{ABC}$ reagent (Vector Laboratories) for $1 \mathrm{~h}$ and rinsed in PBS, $\mathrm{pH}$ 7.4. To visualize the avidin-biotinylated horseradish peroxidase (HRP) complex, the slices were incubated in diaminobenzidine (DAB) for $5 \mathrm{~min}$. The DAB reaction was stopped by washing with $\mathrm{H}_{2} \mathrm{O}$, and the sections were then mounted with VectaMount (Vector). Differential interference contrast images of the sections were made using a Zeiss LSM 5 Pascal laser-scanning microscope (Zeiss) equipped with 10 and $20 \times$ objective lenses.

Cell cultures. The synaptic experiments used sensorimotor cocultures, each consisting of one pleural sensory neuron and one small siphon (LFS-type) motor neuron; the neurons were individually dissociated from central ganglia of Aplysia (60-100 g) and placed into cell culture together (Lin and Glanzman, 1994). The culture medium contained 50\% Aplysia hemolymph and 50\% Leibowitz-15 (L-15; Sigma-Aldrich). The cultures were maintained at $18^{\circ} \mathrm{C}$ for $3-4 \mathrm{~d}$ before the start of the experiments to allow them to form robust monosynaptic connections. The mean size of the sensorimotor EPSPs evoked on the day 1 pretest in the cocultures included in the study was $24.5 \pm 0.9 \mathrm{mV}$. One-way ANOVAs (see below) performed on the pretest EPSPs for each of the synaptic experiments indicated that the group differences were not significant ( $p>0.6$ for each experiment).

Electrophysiology. The electrophysiological methods have been previously described (Lin and Glanzman, 1994; Cai et al., 2008). Briefly, during electrophysiological recording, cocultures were perfused with $50 \%$ sterile ASW and 50\% L-15 (perfusion medium). All experiments were performed at room temperature. Synaptic strength was determined on day 1 by eliciting a single EPSP in the motor neuron using intracellular activation of the sensory neuron (pretest). After this initial synaptic assessment, the microelectrodes were removed from the neurons. 5-HT was prepared fresh daily as a $10 \mathrm{~mm}$ stock solution in ASW, and then diluted to the final concentration of $100 \mu \mathrm{M}$ in the perfusion medium immediately before the first application. To induce LTF, cocultures were treated with repeated, spaced applications of 5-HT (five 5 min applications of 5-HT, $20 \mathrm{~min}$ interval between applications). After each $5 \mathrm{~min}$ application, the 5-HT was rapidly washed out with normal perfusion medium for 15 $\mathrm{min}$. The control cocultures were treated with the perfusion solution alone. After 5-HT or control treatment, the perfusion medium was replaced with culture medium, and the cocultures were returned to the $18^{\circ} \mathrm{C}$ incubator. Forty-eight hours later, the neurons were reimpaled with microelectrodes, and the synaptic strength was reassessed (posttest).

A stock solution of myristoylated $1 \mathrm{~mm}$ ZIP/ScrZIP or $10 \mathrm{~mm}$ chelerythrine was prepared as in the behavioral experiments. The stock solution of ZIP/ScrZIP/chelerythrine was added to the cocultures at $24 \mathrm{~h}$ after the 5-HT treatment, unless otherwise indicated. The final concentration of ZIP/ScrZIP and chelerythrine in the culture medium was 1 and 5-10 $\mu \mathrm{M}$, respectively; the drug treatment period was $1 \mathrm{~h}$. After ZIP or chelerythrine treatment, the drug was washed out of the culture dish with culture medium.

Statistical analyses. The data from the behavioral experiments are the mean \pm SEM. duration (in seconds) of the SWR for each test. The significance of the group differences were first assessed with a repeatedmeasures ANOVA; given significance of the group differences $(p<$ 0.05 ), Student-Newman-Keuls (SNK) post hoc tests were subsequently used for pairwise comparisons. For the synaptic experiments, the peak amplitude of the posttest EPSP was normalized to the amplitude of the pretest EPSP for the same coculture. The membrane input resistances for both neurons (sensory and motor) were measured, and the threshold for evoking an action potential (spike threshold) was determined. The input resistances and the spike threshold obtained in the posttest were normalized to those in the pretest. The normalized data were expressed as means \pm SEM. Nonparametric tests were used to assess the significance of the electrophysiological results. A Mann-Whitney $U$ test was used for a single comparison of two groups. Kruskal-Wallis tests were used to assess the significance of differences among several groups; if the group differences were significant $(p<0.05)$, Dunn's tests were then used for post hoc comparisons between pairs of groups. All reported levels of significance are two-tailed values.

\section{Results}

Treatment with either ZIP or chelerythrine disrupts established LTS of the withdrawal reflex

To explore the possibility that PKM Apl III maintains long-term memory in Aplysia, we tested whether injecting the ZIP (Ling et al., 2002) into animals disrupts previously established LTS. ZIP consists of the autoinhibitory pseudosubstrate sequence of the regulatory domain of $\mathrm{PKC} \zeta$, and this sequence is conserved in PKC Apl III (Bougie et al., 2009). In our experiments, the peptide was injected into an animal's hemocoel through its neck. Gastropod mollusks do not possess a blood-brain barrier (Abbott et al., 1986); furthermore, the CNS of Aplysia is directly and richly vas- 

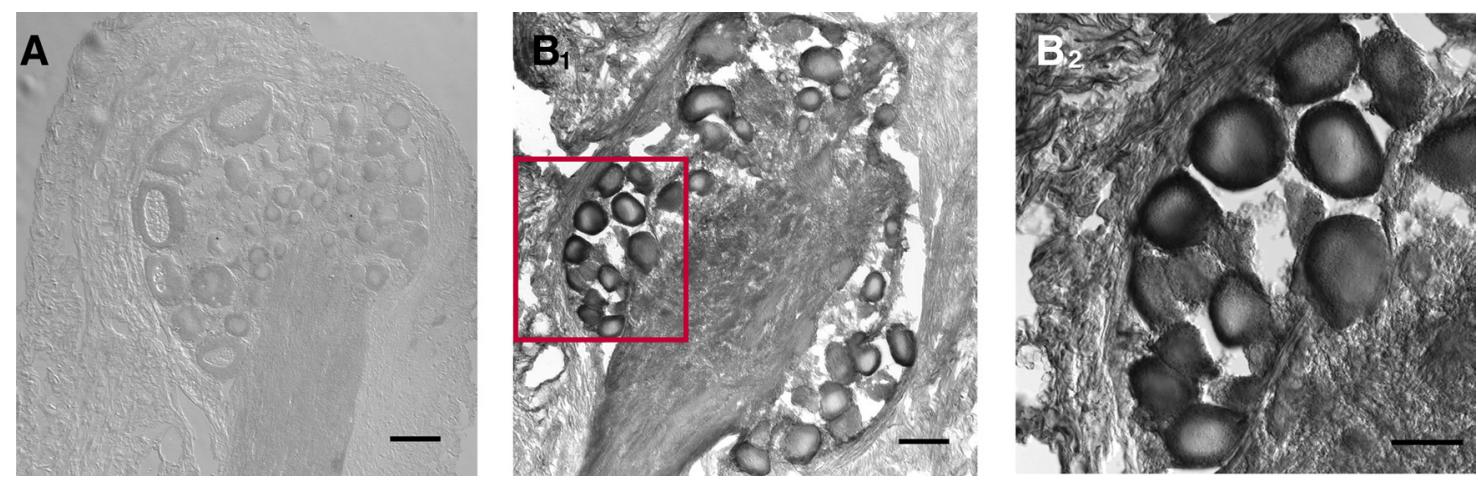

Figure 1. Biotin-labeled ZIP penetrates the connective tissue and enters inside neurons. Biotin-labeled peptide was conjugated to HRP-avidin, and then visualized by DAB reaction (see Materials and Methods). $A$, Low-power micrograph of a cryostat section of the pleural ganglion from an animal given a vehicle injection. Note the absence of DAB staining after biotin detection processing. $\boldsymbol{B}_{1}$, Low-power micrograph of a cryostat section of the pleural ganglion from an animal given an injection of biotin-labeled myristoylated ZIP. $\boldsymbol{B}_{2}$, Higher power micrograph of the area indicated by the red box in $\boldsymbol{B}_{1}$. There is strong immunocytochemical staining in the connective tissue sheath surrounding the ganglion, as well as inside neurons. Scale bars: $\boldsymbol{A}_{,} \boldsymbol{B}_{1}, 100 \mu \mathrm{m} ; \boldsymbol{B}_{2}, 50 \mu \mathrm{m}$.

cularized by a branch of the anterior aorta (Furgal and Brownell, 1987). Therefore, small molecules introduced into the hemolymph would be expected to be rapidly delivered to the abdominal ganglion, as well as the other central ganglia, of Aplysia (Furgal and Brownell, 1987). Nonetheless, to ensure that the inhibitory peptide had free access to neurons of the CNS, we injected biotinylated ZIP (von Kraus et al., 2010) into the hemocoel. The concentration of the biotinylated ZIP in the hemolymph $(\sim 10$ $\mu \mathrm{M}$ ) was the same as the concentration of ZIP used in the behavioral experiments (below). Biotin labeling was clearly evident inside central ganglia; in particular, unambiguous staining was observed inside individual central neurons (Fig. 1). We therefore conclude that the ZIP was able to readily enter central neurons from the hemocoel in living animals, despite the presence of the connective tissue sheath surrounding the ganglia.

To test the ability of ZIP to disrupt long-term memory maintenance, animals were given sensitization training and then tested $24 \mathrm{~h}$ later. Shortly ( $\leq 15 \mathrm{~min}$ ) after the $24 \mathrm{~h}$ test, three groups of animals that had been subjected to sensitization training received an intrahemocoel injection of myristoylated ZIP $(\sim 10 \mu \mathrm{M}$ final concentration in the hemolymph here and in subsequent experiments), the myristoylated, scrambled version of the ZIP peptide (ScrZIP, same concentration as ZIP), or the vehicle $\left(\mathrm{dH}_{2} \mathrm{O}\right)$ (Fig. $2 A, B)$. Two groups of control animals that did not receive sensitization training also received an injection of ZIP or vehicle. The SWR of all animals was tested once more at $48 \mathrm{~h}$. A one-way ANOVA indicated that the group differences for the 24 and $48 \mathrm{~h}$ posttests were highly significant $\left(F_{(4,19)}=18.2\right.$ and $52.1 ; p<$ 0.0001 for the results of each ANOVA). Post hoc tests on the $24 \mathrm{~h}$ data indicated all of the trained groups showed significant sensitization at $24 \mathrm{~h}$ compared with the control groups and that the ZIP injection at $24 \mathrm{~h}$ blocked the expression of sensitization at $48 \mathrm{~h}$. This effect was unlikely to have been attributable to a nonspecific effect of ZIP, because the injection of the scrambled peptide did not affect LTS. Furthermore, there were no significant differences between the Control-Veh and Control-ZIP groups.

The PKC inhibitor chelerythrine is specific for PKM Apl III at low $(\leq 20 \mu \mathrm{M})$ concentrations in Aplysia (Villareal et al., 2009). Accordingly, we examined the effect of a low concentration $(\sim 20$ $\mu \mathrm{M}$ in the hemolymph here and in subsequent experiments) of chelerythrine on maintenance of LTS (Fig. 2C). The behavioral testing and training methods, and injection method were the same as in the ZIP experiments. There were four groups as follows: Control-Veh $(n=6)$, Control-Chelerythrine (Chel) $(n=$ $5)$, Trained-Veh $(n=7)$, and Trained-Chel $(n=7)$. The differ- ences among the groups were highly significant for both the 24 and $48 \mathrm{~h}$ posttests (one-way ANOVAs; $F_{(3,21)}=24.1$ and 18.4; $p<0.0001$ for both posttests). The two trained groups showed significant sensitization at $24 \mathrm{~h}$, as indicated by post hoc comparisons with their respective control groups. Trained animals that received an injection of vehicle solution were also sensitized at $48 \mathrm{~h}$, but sensitization was absent in the trained animals treated with chelerythrine. Although, like ZIP, chelerythrine disrupted maintenance of LTS, the drug did not appear to have a deleterious effect on the animals, as indicated by the lack of significant differences between the Control-Veh and Control-Chel groups on any of the post hoc comparisons.

\section{The disruption of LTS by inhibition of PKM is distinct from memory reconsolidation}

Because we elicited the SWR just before the injection of ZIP/ chelerythrine, it could be argued that the lack of LTS in the experimental animals at $48 \mathrm{~h}$ was attributable to disruption of memory reconsolidation triggered by the $24 \mathrm{~h}$ posttest (Nader et al., 2000a; Sara, 2000). To evaluate this explanation for our data, we repeated the chelerythrine experiment, omitting the $24 \mathrm{~h}$ posttest (Fig. 3A). As in our previous experiment (Fig. 2C), some animals (Trained-Chel, $n=4$ ) received an intrahemocoel injection of chelerythrine $24 \mathrm{~h}$ after sensitization training. Another group (Trained-Veh, $n=8$ ) received an injection of the vehicle at $24 \mathrm{~h}$ after training. The third group (Control-Veh, $n=4$ ) also received an injection of the vehicle at $24 \mathrm{~h}$, but was not trained. [We did not include a control chelerythrine group in this experiment, or in the experiment presented in Fig. 3B (below), because we previously found that the chelerythrine injection had no effect on the SWR (Fig. 2C).] All three groups were given just a single posttest at $48 \mathrm{~h}$. The differences among the groups on the $48 \mathrm{~h}$ posttest were highly significant (one-way ANOVA; $F_{(2,13)}=34.7$; $p<0.0001)$. The Trained-Veh group, but not the Trained-Chel group, exhibited sensitization at $48 \mathrm{~h}$. Thus, the apparent elimination of established LTS by chelerythrine did not depend on evoking the SWR immediately preceding the drug injection and cannot be attributed to disruption of memory reconsolidation.

\section{After its disruption, the memory for LTS does not} spontaneously recover and cannot be reinstated by brief sensitization training

After their extinction, conditioned reflexes can exhibit spontaneous recovery with the passage of time, or be reinstated if the animal is exposed to the original unconditioned stimulus ( Re- 

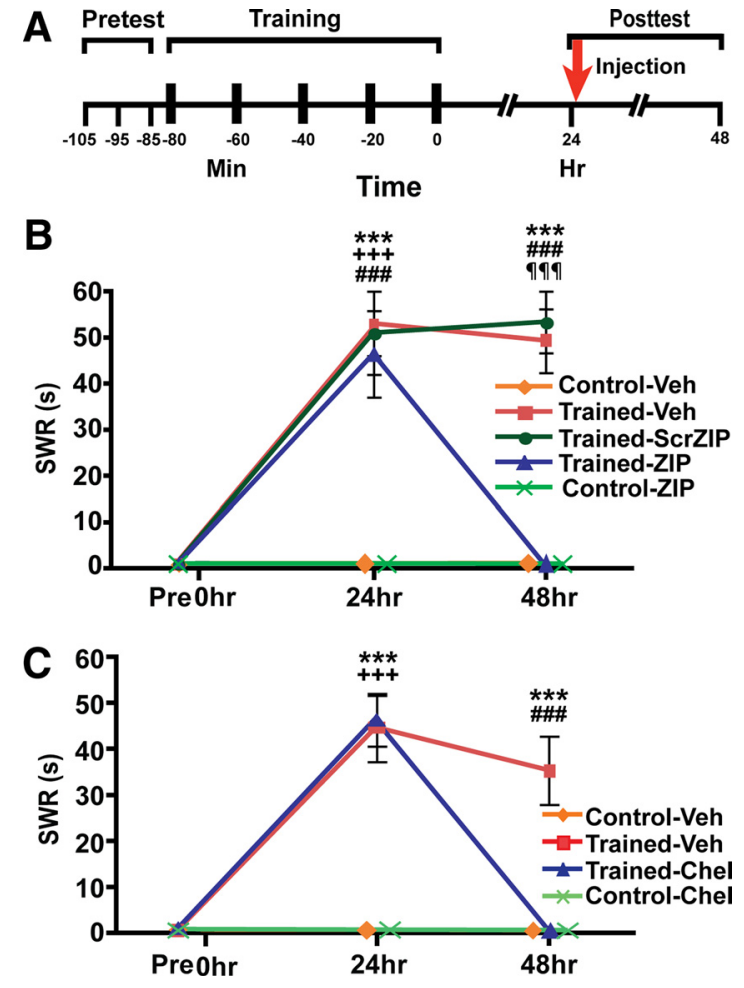

Figure 2. Inhibiting PKM Apl III disrupts established LTS in Aplysia.A, Experimental protocol. The timing of the pretests, training, posttests, and drug/vehicle injections is shown relative to the end of the last training session. The time of the intrahemocoel injection of either drug or vehicle is indicated by the red arrow in this figure and in Figures $3-5$ (below). B, ZIP treatment at $24 \mathrm{~h}$ after training blocked LTS. Animals in all three trained groups exhibited significant sensitization at $24 \mathrm{~h}$, as indicated by SNK post hoc tests. Thus, the SWR was longer in the Trained-Vehicle (Veh) group $(n=4)$ than in the Control-Veh group $(n=6)(q=8.6 ; p<$ $0.001)$, in the Trained-ZIP group $(n=6)$ than in the Control-ZIP group $(n=4)(q=7.4$; $p<0.001)$, and in the Trained-ScrZIP group $(n=4)$ than in the Control-ZIP group $(q=6.6$; $p<0.001$ ). The Trained-Veh and Trained-ScrZIP groups also exhibited significant sensitization at $48 \mathrm{~h}$, compared with their respective control groups: Trained-Veh versus Control-Veh, $q=$ $13.8(p<0.001)$; and Trained-ScrZIP versus Control-ZIP, $q=12.4(p<0.001)$. By contrast, the Trained-ZIP animals did not exhibit sensitization at $48 \mathrm{~h}$. Thus, the SWR in the TrainedScrZIP animals was significantly longer than that in the Trained-ZIP animals $(q=13.6 ; p<$ 0.001), and there was no significant difference between the Trained-ZIP and Control-ZIP groups. Notice that there were no significant differences between the Trained-Veh and TrainedScrZIP data for either the 24 or $48 \mathrm{~h}$ test. Also, the differences between the Control-Veh and Control-ZIP groups were not significant in the experiments in $\boldsymbol{B}$, or in any of our other experiments. Asterisks, Comparison between Trained-Veh and Control-Veh groups; plus signs, comparison between Trained-ZIP and Control-ZIP groups; pound signs, comparison between Trained-ScrZIP and Control-ZIP groups; and paragraph signs, comparison between the TrainedScrZIP and Trained-ZIP groups. Here and in subsequent figures, one symbol indicates $p<0.05$; two symbols, $p<0.01$; three symbols, $p<0.001$. C, Chelerythrine treatment at $24 \mathrm{~h}$ also disrupted established LTS. SNK post hoc comparisons indicated that the training produced significant LTS in the Trained-Veh and Trained-Chel groups at $24 \mathrm{~h}$ [Trained-Veh vs Control-Veh, $q=8.6(p<0.001)$, and Trained-Chel vs Control-Chel, $q=8.4(p<0.001)$ ]. Sensitization was also evident at $48 \mathrm{~h}$ in the Trained-Veh group [Trained-Veh vs Control-Veh, $q=8.4$ ( $p<$ $0.001)]$, but not in the Trained-Chel group. The difference between the two trained groups on the $48 \mathrm{~h}$ test was highly significant $(q=8.8 ; p<0.001)$. There was no significant difference between the Trained-Chel and Control-Chel groups at $48 \mathrm{~h}$. Also, there were no significant differences between the two control groups at either 24 or $48 \mathrm{~h}$. Asterisks, As in $\boldsymbol{B}$, plus signs indicate comparison between Trained-Chel and Control-Veh groups; pound signs, comparison between the Trained-Veh and Trained-Chel groups. Data in this figure, and in Figures 3-5, are the mean duration (in seconds) of the SWR. Error bars in this and subsequent figures represent SEM.

scorla and Heth, 1975). Sensitization is, of course, a nonassociative form of learning; nonetheless, we wanted to know whether LTS would show either spontaneous recovery or reinstatement after its apparent elimination by inhibition of PKM Apl III. In this
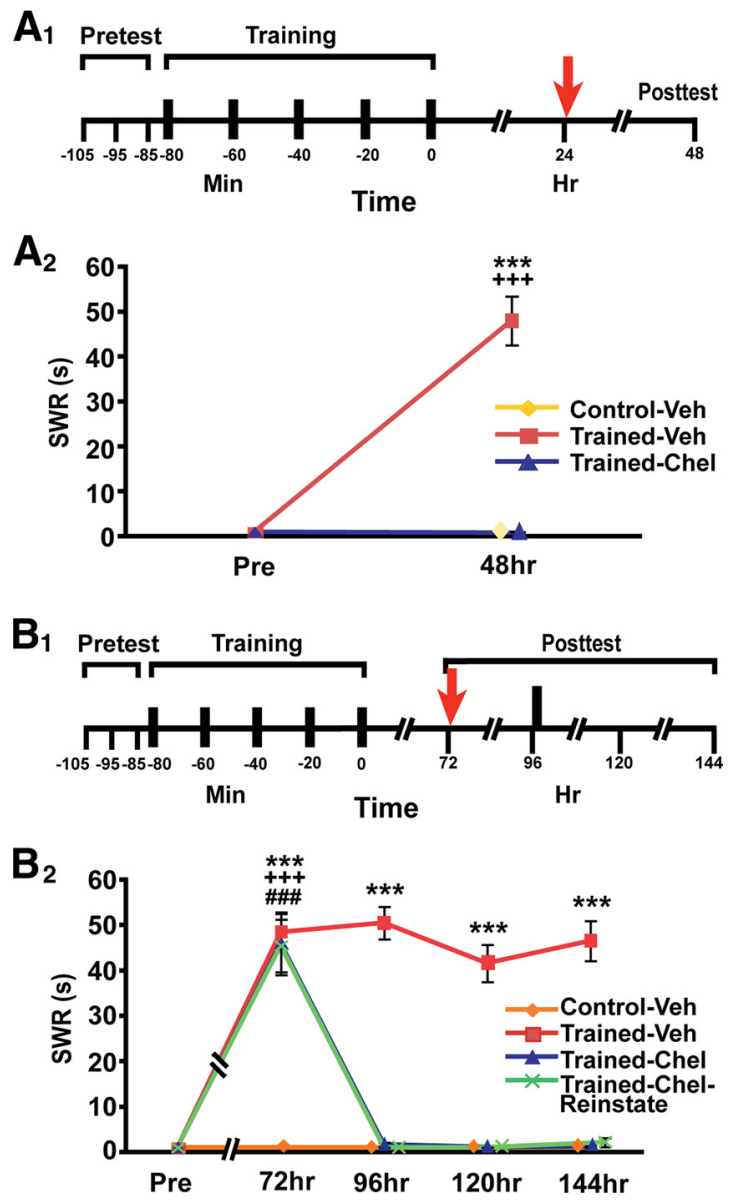

Figure 3. Disruption of established LTS is not a reconsolidation-related phenomenon, and once disrupted, LTS exhibits neither spontaneous recovery nor reinstatement. $\boldsymbol{A}_{\boldsymbol{1}}, \boldsymbol{B}_{1}$, Experimental protocols (see Fig. 2). In the experiments in $\boldsymbol{A}_{1}$, the animals did not receive a posttest $24 \mathrm{~h}$ after training. In the experiments in $\boldsymbol{B}_{1}$, some animals received one additional bout of sensitization training (black bar) immediately after the $96 \mathrm{~h}$ posttest. $\boldsymbol{A}_{2}$, Chelerythrine disrupted established LTS despite the absence of a posttest at $24 \mathrm{~h}$. Post hoc tests revealed that the mean SWR in the Trained-Veh group $(n=8)$ was significantly sensitized compared with that in the Control-Veh group $[n=4 ; q=9.6(p<0.001)]$, and the Trained-Chel group $[n=4 ; q=$ $9.6(p<0.001)]$. The Control-Veh and Trained-Chel groups did not differ significantly. Asterisks, Comparison between Trained-Veh and Control-Veh groups; plus signs, comparison between the Trained-Veh and Trained-Chel groups. $\boldsymbol{B}_{\mathbf{2}}$, Absence of spontaneous recovery or reinstatement of LTS after the chelerythrine injection. Animals in the Trained-Chel-Reinstate group were given one additional bout of sensitization training immediately after the $96 \mathrm{~h}$ posttest $\left(\boldsymbol{B}_{1}\right.$, black bar). Sensitization was robust in all three trained groups at $72 \mathrm{~h}$ posttraining, as indicated by post hoc tests [Trained-Veh vs Control-Veh $(q=10.1, p<0.001)$, Trained-Chel vs Control-Veh $(q=8.4, p<0.001)$, and Trained-Chel-Reinstate vs Control-Veh $(q=8.3, p<$ $0.001)]$. However, although the Trained-Veh group exhibited sensitization on all of the subsequent posttests [for the comparison between the Trained-Veh and Control-Veh groups, $q=$ $18.3(p<0.001)$ at $96 \mathrm{~h} ; q=13.1(p<0.001)$ at $120 \mathrm{~h}$; and $q=13.5(p<0.001)$ at $144 \mathrm{~h}]$, sensitization was absent in both groups of chelerythrine-treated animals after $72 \mathrm{~h}$. Post hoc tests revealed no significant differences for any of the comparisons between the Control-Veh group and the Trained-Chel and Trained-Chel-Reinstate groups on any of the post-72 $\mathrm{h}$ tests. Asterisks, Comparison between the Trained-Veh and Control-Veh groups; plus signs, comparison between Trained-Chel and Control-Veh groups; pound signs, comparison between TrainedChel-Reinstate and Control-Veh groups.

experiment, animals were first retested at $72 \mathrm{~h}$ after training (or at the equivalent time in the control group). Chelerythrine was injected into two groups of animals at $72 \mathrm{~h}$ after LTS training, and then at $96 \mathrm{~h}$ after training one of the groups (Trained-ChelReinstate group) received an additional bout (three $1 \mathrm{~s}$ trains) of tailshocks (Fig. 3B). (Notice that this training comprises one-fifth of the number of tailshocks used to induce LTS.) The SWR was 
tested at 72, 96, 120, and $144 \mathrm{~h}$ after sensitization training in the trained groups, or at the equivalent times in the control group. There were three groups of trained animals-Trained-Veh $(n=$ 13), Trained-Chel $(n=7)$, and Trained-Chel-Reinstate $(n=$ 7 ) - and a single control group (Control-Veh, $n=7$ ). [We did not include a control group treated with chelerythrine alone in this experiment because we had previously found that the chelerythrine treatment had no effect on the baseline SWR (Fig. 2C).] The differences among the four groups were highly significant for each of the posttests (one-way ANOVAs, $F_{(3,30)}$ for $72 \mathrm{~h}=19.5$, $p<0.0001 ; F_{(3,30)}$ for $96 \mathrm{~h}=97.4, p<0.0001 ; F_{(3,30)}$ for $120 \mathrm{~h}=$ 50.3, $p<0.0001$; and $F_{(3,30)}$ for $\left.144 \mathrm{~h}=52.8, p<0.0001\right)$. All three trained groups exhibited significant LTS at $72 \mathrm{~h}$ after training. But after the drug injection, only the Trained-Veh group subsequently exhibited sensitization; there was no evidence of spontaneous recovery of sensitization for the $72 \mathrm{~h}$ period after chelerythrine injection in either the Trained-Chel or the TrainedChel-Reinstate groups. Furthermore, the additional bout of sensitization training at $96 \mathrm{~h}$ failed to reinstate LTS in the Trained-Chel-Reinstate group.

\section{Treatment with chelerythrine or ZIP disrupts LTS even 1 week after training}

The above results provide compelling evidence that an early stage (24-72 h) of memory maintenance for LTS in Aplysia requires ongoing activity of PKM Apl III. However, LTS of the SWR has been shown to persist for at least 3 weeks (Pinsker et al., 1973). To test whether the maintenance of later stages of the memory for LTS also depends on PKM Apl III, animals were treated with chelerythrine at 1 week after sensitization training (Fig. 4A). The drug was injected into the animals immediately after the SWR was tested at day 7 to assess whether the training produced sensitization that lasted at least 1 week; the animals were then retested on days 8 and 9 . There were two trained groups of animals [Trained-Veh $(n=5)$ and Trained-Chel $(n=5)]$ and two control groups [Control-Veh $(n=4)$ and Control-Chel $(n=3)]$. Oneway ANOVAs indicated that the overall differences among the four groups were highly significant on all of the posttests (day 7 , $F_{(3,13)}=22.7, p<0.0001$; day $8, F_{(3,13)}=15.4, p<0.001$; and day 9, $\left.F_{(3,13)}=12.9, p<0.001\right)$. Post hoc tests showed that the Trained-Veh group exhibited significant sensitization 7-9 d after training compared with the Control-Veh group. The SWR in the TrainedChel group was significantly sensitized compared with the Control-Chel group on the day 7 posttest, but not on either the day 8 or day 9 posttest. Finally, there was no difference between the Control-Veh and Control-Chel groups on any of the posttests, indicating that the chelerythrine did not affect the baseline SWR. These results demonstrate that LTS was present in the Trained-Chel group on day 7 after training but was absent on days 8 and 9. Therefore, the chelerythrine injection disrupted the week-old memory for LTS, and the disrupted memory did not spontaneously recover over the next $2 \mathrm{~d}$.

We also tested the effect of an injection of the peptide inhibitor ZIP on 1-week-old memory for sensitization (Fig. 4B). The design of this experiment was similar to that in the test of chelerythrine above (Fig. $4 A$ ), but we did not test the SWR before the ZIP injection at day 7 to exclude a contribution from disruption of memory reconsolidation to any resulting positive results. Three groups were included: Trained-Veh $(n=5)$, Trained-ZIP $(n=5)$, and Control-Veh $(n=5)$. [Neither a Control-ZIP group nor a Trained-Scr-ZIP group was included in this experiment because we did not observe any effect of ZIP on the baseline SWR nor a disruptive effect of the scrambled peptide on sensitization,
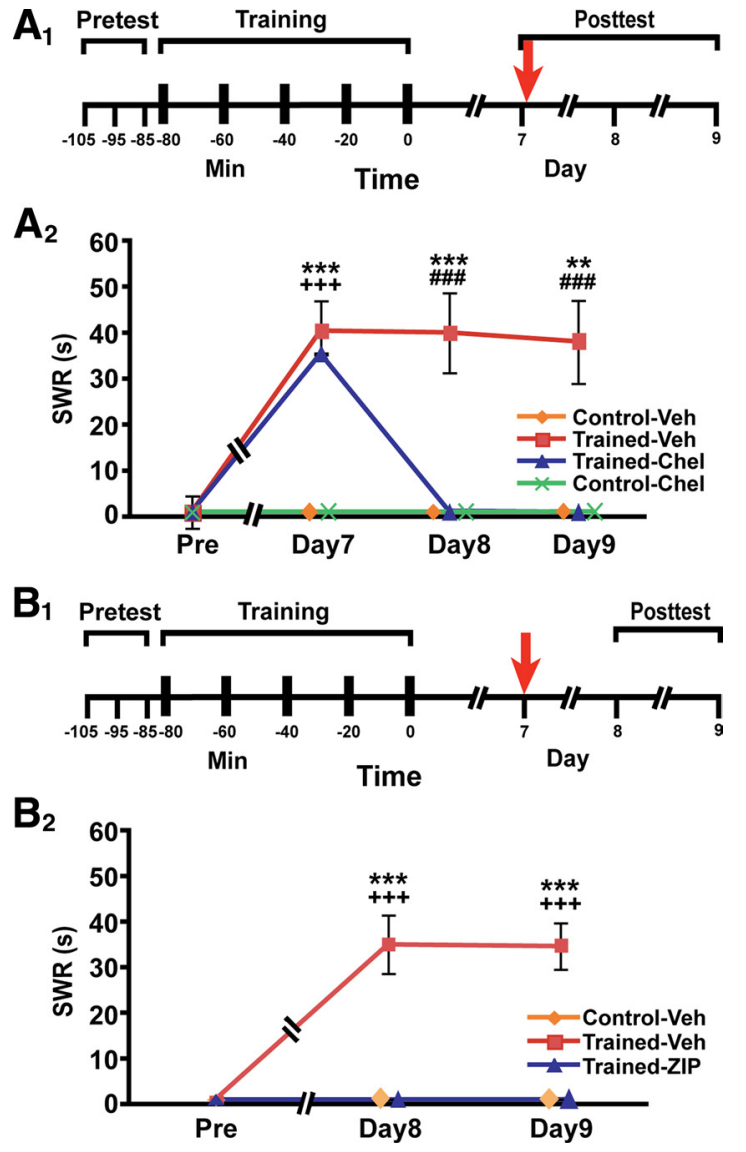

Figure 4. The effect of chelerythrine or ZIP treatment at $7 \mathrm{~d}$ after training. $\boldsymbol{A}_{\boldsymbol{1}}, \boldsymbol{B}_{\boldsymbol{1}}$, Experimental protocols, as in Figure 2. $\boldsymbol{A}_{\mathbf{2}}$, Chelerythrine injection at day 7 blocked the subsequent expression of LTS. There was significant LTS at day 7 before vehicle/chelerythrine injection in both the Trained-Veh group [Trained-Veh vs Control-Veh, $q=9.1(p<0.001)$ ] and TrainedChel group [Trained-Chel vs Control-Chel, $q=7.3(p<0.001)$ ]. The Trained-Veh group also exhibited robust sensitization compared with the Control-Veh group on days $8[q=7.6$ ( $p<$ $0.001)]$ and $9[q=7.0(p<0.01)]$. But sensitization was not apparent in the Trained-Chel group after the injection of chelerythrine, as indicated by the lack of significance in the day 8 and 9 comparisons between the two chelerythrine-treated groups. Also, the duration of the SWR was significantly longer in the Trained-Veh group than in the Trained-Chel group on posttraining days $8[q=8.1(p<0.001)]$ and $9[q=7.4(p<0.001)]$. Asterisks, Comparison between the Trained-Veh and Control-Veh groups; plus signs, comparison between Trained-Chel and Control-Chel groups; pound signs, comparison between the Trained-Veh and Trained-Chel groups. $\boldsymbol{B}_{2}$, ZIP injection at day 7 also blocked subsequent LTS. The training produced significant LTS in the Trained-Veh group at days 8 and 9 , as indicated by the comparison with the ControlVeh group [day 8 comparison, $q=9.2(p<0.001)$; day 9 comparison, $q=11.4(p<0.001)$ ]. However, after the injection of ZIP, sensitization was no longer apparent in the Trained-ZIP, as indicated by the lack of a significant difference between the Trained-ZIP and Control-Veh groups. Moreover, animals in the Trained-Veh group were significantly more sensitized than those in the Trained-ZIP group on both posttraining tests [day 8 comparison, $q=9.2$ ( $p<$ $0.001)$; day 9 comparison, $q=11.4(p<0.001)$ ]. Notice that there was no posttest preceding the injection of ZIP/vehicle solution at day 7. Asterisks, Comparison between the Trained-Veh and Control-Veh groups; plus signs, comparison between Trained-Veh and Trained-ZIP groups.

in our previous behavioral experiment (Fig. 2B).] The group differences for the posttests on days 8 and 9 were highly significant (day 8, one-way ANOVA, $F_{(2,12)}=28.3, p<0.0001$; day 9, one-way ANOVA, $\left.F_{(2,12)}=43.5, p<0.001\right)$. Post hoc tests showed that Trained-Veh group was significantly sensitized on the posttests compared with both the Control-Veh and TrainedZIP groups. Therefore, the week-old memory for LTS appeared to be eliminated when PKM Apl III activity was inhibited with ZIP. 

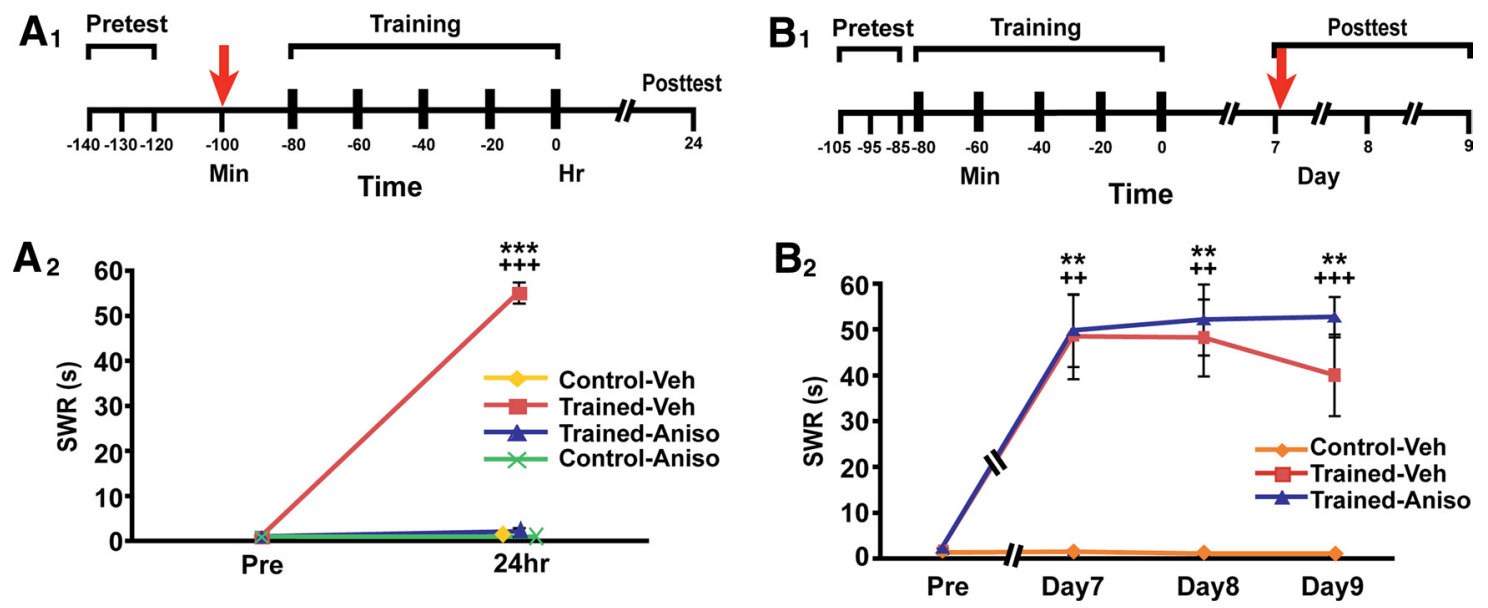

Figure 5. Anisomycin disrupts the induction, but not the maintenance, of LTS. $A_{1}, B_{1}$, Experimental protocols, as in Figure $2 . A_{2}$, Anisomycin injection before training blocked the induction of LTS. The mean SWR in the Trained-Veh group was significantly sensitized compared with that in the Control-Veh group [SNK test, $q=38.4(p<0.001)$ ] and the Trained-Aniso group [SNK test, $q=$ 40.0 ( $p<0.001)$ ]. The differences among the Control-Veh, Control-Aniso, and Trained-Aniso groups were not significant. Asterisks, Comparison between the Trained-Veh and Control-Veh groups; plus signs, comparison between the Trained-Veh and Trained-Aniso groups. $\boldsymbol{B}_{2}$, Anisomycin injection on day 7 fails to disrupt LTS expression on days 8 and 9 . Post hoc tests revealed that the Trained-Veh group was significantly sensitized compared with the Control-Veh groups on each of the three posttests [day $7, q=5.5(p<0.01)$; day $8, q=5.8(p<0.01)$; day $9, q=5.9(p<$ $0.01)$ ]. The comparison between the Trained-Aniso and Control-Veh groups was also significant on days 7-9 [day 7, $q=5.9(p<0.01)$; day $8, q=6.6(p<0.01)$; day $9, q=8.2(p<0.001)$ ]. [A Control-Aniso group was not included in this experiment because we previously found (see $A_{2}$ ) that anisomycin treatment alone had no effect on the SWR.] The differences between the Trained-Veh and Trained-Aniso groups were not significant on any of the posttests. Asterisks, Comparison between Trained-Veh and Control-Veh groups; plus signs, comparison between Trained-Aniso and Control-Veh groups.

\section{Inhibition of protein synthesis 1 week after training does not disrupt LTS}

Recent work has implicated the Aplysia homolog of CPEB (ApCPEB) in the maintenance of LTS. According to one model, ApCPEB, when activated by sensitization-related stimulation, becomes constitutively active and drives local protein synthesis; this ApCPEB-dependent ongoing protein synthesis, it is believed, plays a critical role in maintaining LTS (Si et al., 2003 b, 2010). In support of this idea, inhibition of protein synthesis has been reported to reverse LTF of the sensorimotor synapse $24-48 \mathrm{~h}$ after training (Miniaci et al., 2008). Until now, however, empirical support for a role for ApCPEB in memory maintenance in Aplysia has come exclusively from experiments on isolated synapses in dissociated cell culture ( $\mathrm{Si}$ et al., 2003a,b, 2010; Miniaci et al., 2008); the potential role of ApCPEB in maintaining memory after actual learning in Aplysia has not been examined. This information is critical to understanding how the memory for LTS persists in Aplysia because our evidence (above) suggests that a requirement for PKM Apl III in long-term memory maintenance may temporally overlap, at least partly, with that for ApCPEB (Miniaci et al., 2008). As an initial step toward delineating the relative roles of ApCPEB and PKM Apl III in the persistence of the memory for LTS, therefore, we tested whether temporarily inhibiting protein synthesis can disrupt well consolidated LTS.

To ascertain the efficacy of our method for inhibiting translation in Aplysia, we first confirmed a previous finding (Castellucci et al., 1989) that induction of LTS requires protein synthesis. Twenty minutes before the start of an experiment, one group of animals [Trained-Aniso group $(n=5)$ ] received an intrahemocoel injection of anisomycin (final concentration in the hemolymph was $\sim 40 \mu \mathrm{M}$ in $0.1 \%$ DMSO), whereas another group [Trained-Veh group $(n=5)$ ] received an injection of the vehicle (DMSO in artificial seawater). There were two untrained control groups, one that received an injection of the vehicle solution [Control-Veh group $(n=4)$ ] and another that received an injection of anisomycin in DMSO [Control-Aniso $(n=4)$ ] at the equivalent time in the experiment as the trained groups. Before training, the duration of the SWR in response to light touch of the siphon was measured in a series of three pretests spaced $10 \mathrm{~min}$ apart (Fig. $5 A$ ). Some animals then received the tailshock sensitization training. Twenty-four hours after the training, or at the equivalent time in control animals, the SWR was retested. There was a single posttest at $24 \mathrm{~h}$ after training (or at the equivalent time for the controls). The overall differences among the groups on the posttest were highly significant (one-way ANOVA; $F_{(3,14)}=$ 393.2; $p<0.0001)$. The Trained-Veh group was significantly sensitized compared with both the Control-Veh and TrainedAniso groups. There were no significant differences among the Control-Veh, Control-Aniso, and Trained-Aniso groups. Thus, as previously reported (Castellucci et al., 1989), treatment with anisomycin before sensitization training blocks the induction of LTS.

Next, we tested whether the anisomycin treatment could disrupt well established LTS. Two groups of animals received LTS training (Fig. 5B). The SWR of both groups was tested 1 week later. One of the trained groups [Trained-Veh $(n=4)$ ] then received an intrahemocoel injection of the vehicle solution, whereas the other group [Trained-Aniso $(n=5)$ ] received an injection of the protein synthesis inhibitor. An untrained group [Control-Veh $(n=5)$ ] was given an injection of the vehicle solution on day 7. (The previous experiment indicated that the anisomycin injection did not affect the baseline SWR, so an anisomycin-injected control group was not included.) The SWR of the animals in each group was then retested on days 8 and 9. The overall group differences were significant for each of the posttests, as indicated by one-way ANOVAs (day $7, F_{(2,9)}=10.2$, $p<0.005$; day $8, F_{(2,9)}=12.1, p<0.003$; and day $9, F_{(2,9)}=$ $17.3, p<0.001)$. There were no significant differences between the two trained groups on any of the posttests. Therefore, by 1 week after training, temporary inhibition of protein synthesis does not disrupt the memory for LTS. 

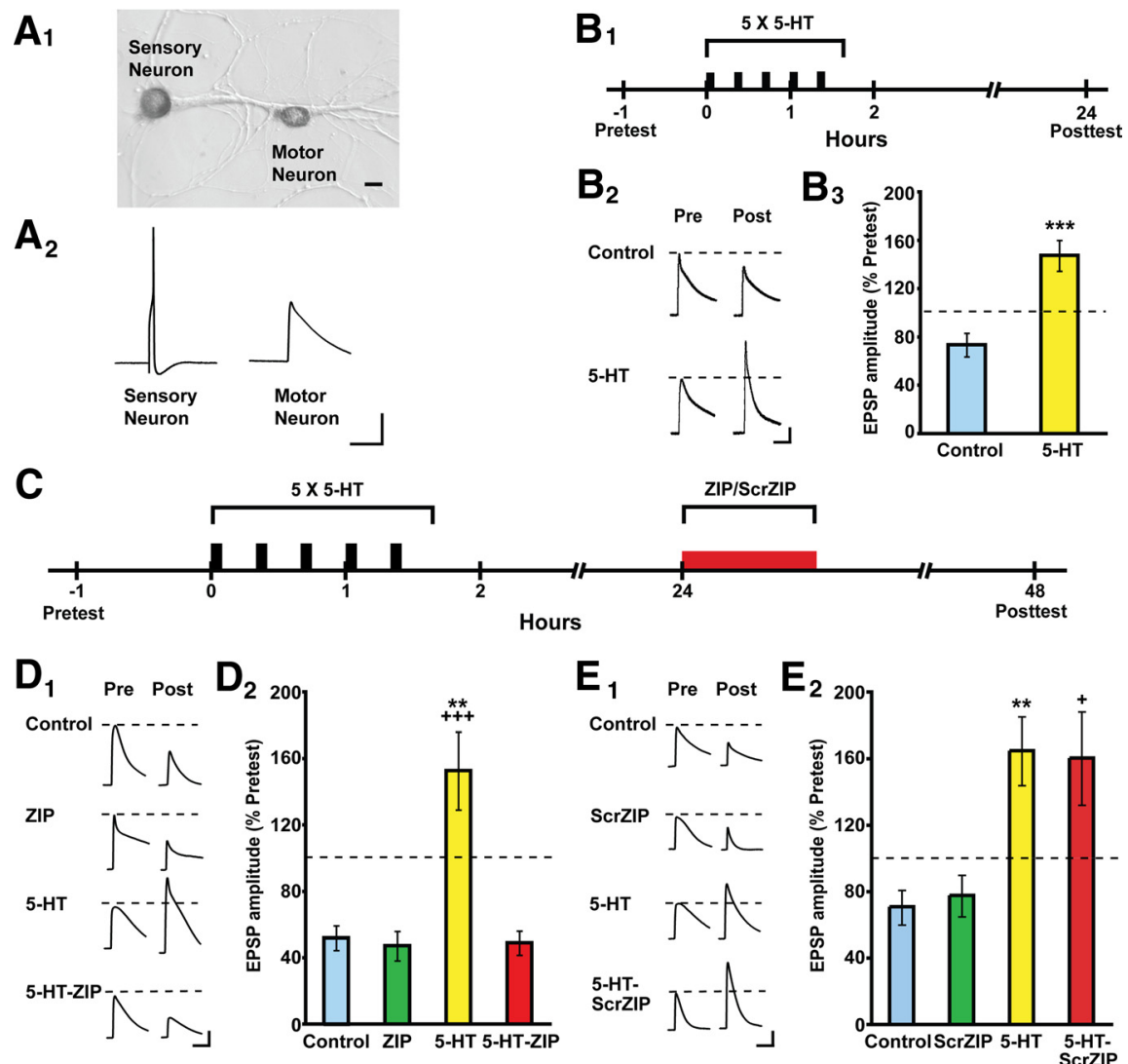

$E_{1} \quad$ Pre Post $E_{2}$
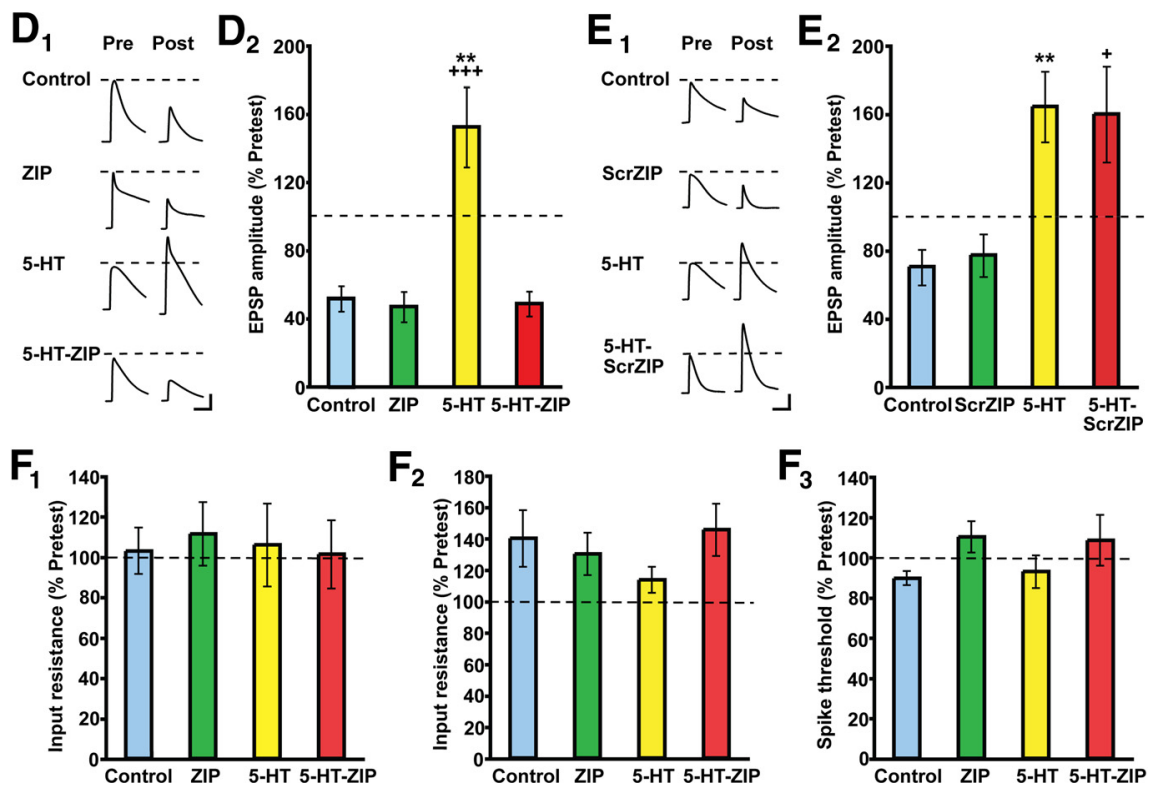

Figure 6. Maintenance of LTF in Aplysia depends on PKM Apl III. $A_{1}$, Sensorimotor coculture. Scale bar, $20 \mu \mathrm{m} . \boldsymbol{A}_{2}$, Sample electrophysiological records from a pretest of a synapse. Calibration: $20 \mathrm{mV}, 200 \mathrm{~ms}$. $\boldsymbol{B}_{1}$, Experimental protocol for the demonstration of $24 \mathrm{~h} \mathrm{LTF.} \boldsymbol{B}_{2}$, Sample EPSPs. Each pair of traces shows EPSPs recorded from the same sensorimotor synapse on day 1 (Pre) and $\sim 24 \mathrm{~h}$ later (Post). Training with 5-HT (100 $\mu \mathrm{m}$ ) produced LTF (bottom traces). Calibration (in this and subsequent panels, as well as Fig. 7): $10 \mathrm{mV}, 80 \mathrm{~ms} . \boldsymbol{B}_{3}, 5$-HT-trained synapses showed significant LTF at $24 \mathrm{~h}$. Data in this figure and in Figure 7 are the mean normalized amplitude of the posttest EPSPs. The mean normalized EPSP in the synapses "trained" with $5-\mathrm{HT}$ ( 5 -HT group, $n=10$ ) at $24 \mathrm{~h}$ after training was $147 \pm 13 \%$, whereas the mean EPSP in the Control group $(n=10)$ was $74 \pm 10 \%(U=6.0 ; p<0.001)$. C, Protocol for the synaptic experiments using ZIP/ScrZIP. Twenty-four hours after 5 -HT training, some cocultures were treated with $1 \mu \mathrm{m} \mathrm{ZIP/ScrZIP}$ for $1 \mathrm{~h}$, after which the ZIP/ScrZIP was rapidly washed out with culture medium. $\boldsymbol{D}_{1}$, Sample EPSPs. $\boldsymbol{D}_{2}$, ZIP treatment at $24 \mathrm{~h}$ blocked the subsequent expression of LTF. Dunn's post hoc tests indicated that the mean normalized EPSP at the $48 \mathrm{~h}$ posttest in the 5 -HT group ( $153 \pm 23 \% ; n=17)$ was significantly greater than those in the Control $(52 \pm 8 \% ; n=15)$ and 5 -HT-ZIP ( $50 \pm$ $7 \% ; n=15)$ groups [5-HT vs Control, $Q=22.0(p<0.01) ; 5$-HT vs 5-HT-ZIP, $Q=24.2(p<0.001)$ ]. There was no significant difference between the EPSPs in the 5-HT-ZIP and ZIP alone ( $47 \pm 9 \% ; n=11)$ groups, nor between the Control and ZIP groups. Asterisks, Comparison between the 5 -HT and Control groups; plus signs, comparison between the 5-HT and 5 -HT-ZIP groups. $\boldsymbol{E}_{1}$, Sample EPSPs. $\boldsymbol{E}_{2}$, Treatment of the sensorimotor synapses with the scrambled ZIP peptide at $24 \mathrm{~h}$ did not block the expression of LTF. As indicated by Dunn's post hoc tests, the mean normalized EPSP at $48 \mathrm{~h}$ in the 5 -HT group $(165 \pm 21 \% ; n=13)$ was significantly greater than those for the Control group $[71 \pm 10 \%, n=13 ; Q=20.2(p<$ $0.01)]$. Moreover, the mean normalized EPSP in the 5 -HT-ScrZIP group $(161 \pm 28 \% ; n=11)$ was significantly greater than that in the Control-ScrZIP group [78 $\pm 12 \%, n=10 ; Q=16.2(p<0.05)]$. There was no significant difference between the EPSPs in the 5-HT and 5-HT-ScrZIP groups, nor between the Control and ScrZIP groups. Asterisks, Comparison between the 5-HT and Control groups; plus signs, comparison between the 5-HT-ScrZIP and ScrZIP alone groups. $\boldsymbol{F}_{1}$, There were no significant changes in the mean input resistance of the sensory neurons in the experiments shown in $\boldsymbol{D}$. $\boldsymbol{F}_{2}$, The mean input resistance of the motor neurons in these experiments also did not change (same cocultures as in $\boldsymbol{F}_{7}$ ). $\boldsymbol{F}_{\mathbf{3}^{2}}$, ZIP treatment did not alter the mean spike threshold of the sensory neurons (experiments shown in $\boldsymbol{D}$ ).
Treating sensorimotor synapses with either ZIP or chelerythrine $24 \mathrm{~h}$ after 5-HT training disrupts LTF

LTF of the monosynaptic connection between the siphon sensory and motor neurons mediates, at least partly, behavioral sensitization of the SWR (Frost et al., 1985). Accordingly, we wanted to know whether PKM Apl III activity maintains LTF, as well as LTS. Long-term ( $\geq 24 \mathrm{~h}$ ) facilitation can be induced in synapses between sensory and motor neurons in dissociated cell culture by repeated treatment with 5-HT (Montarolo et al., 1986). We therefore tested whether inhibition of PKM Apl III disrupts maintenance of LTF of the in vitro sensorimotor connection. As previously reported (Cai et al., 2008), five spaced 5 min bouts of 5 -HT $(100 \mu \mathrm{M})$ produced significant LTF of the EPSP at the synapse between a single pleural sensory neuron and a single small siphon (LFS) motor neuron in dissociated cell culture (Mann-Whitney test, $U=6.0$; $p<0.001$ ) (Fig. 6A,B). However, when synapses were treated with myristoylated ZIP ( $1 \mu \mathrm{M} ; 1 \mathrm{~h}) \sim 24 \mathrm{~h}$ after the 5-HT "training," facilitation was absent $24 \mathrm{~h}$ later ( $\sim 48 \mathrm{~h}$ after 5 -HT training); by contrast, synapses trained with 5-HT, but not treated with ZIP at $24 \mathrm{~h}$ were significantly facilitated at $48 \mathrm{~h}$ (Fig. 6D). A nonparametric ANOVA performed on the group data for the $48 \mathrm{~h}$ posttest showed that the differences among the groups were highly significant (Kruskal-Wallis test; $H=23.7$; $p<0.0001)$. Post hoc tests indicated that there was significant facilitation at $48 \mathrm{~h}$ in the 5-HT trained group, but not in the group treated with ZIP $24 \mathrm{~h}$ after 5-HT training. The EPSPs in synapses treated with PKM inhibitor alone did not differ from those in Control synapses. Therefore, the myristoylated ZIP had no apparent effect on baseline synaptic transmission.

To control for the potential nonspecific effects of the peptide treatment on synaptic facilitation, we performed additional experiments in which sensorimotor cocultures were treated with the scrambled ZIP peptide at $24 \mathrm{~h}$ after 5-HT training; other cocultures were treated with ScrZIP alone at the equivalent time point. Treatment of the cocultures with ScrZIP $24 \mathrm{~h}$ after 5-HT training did not disrupt the expression of LTF at $48 \mathrm{~h}$ (Fig. 6E). The differences among the groups at $48 \mathrm{~h}$ in this experiment (Fig. $6 E_{2}$ ) were highly significant (Kruskal-Wallis test; $H=$ $21.4 ; p<0.0001$ ). Post hoc tests showed that both the 5-HT and 5-HT-ScrZIP groups were significantly facilitated at 48 h compared with the Control and ScrZIP alone groups, respectively. 
Notice that in none of the experiments presented in Figure 6, $D$ and $E$, were the synapses tested at $24 \mathrm{~h}$, so our results could not be attributable to a reconsolidation-related phenomenon. Furthermore, we observed no significant differences among the groups with respect to the input resistances of the sensory and motor neurons, or in the spike thresholds of the sensory neurons (Fig. 6F).

We also tested the effect of chelerythrine treatment on established LTF. As was true for ZIP, applying chelerythrine (5-10 $\mu \mathrm{M} ; 1 \mathrm{~h}$ ) to sensorimotor cocultures $24 \mathrm{~h}$ after 5-HT training blocked the expression of LTF at $48 \mathrm{~h}$ after training (Fig. $7 \mathrm{~A}$ ). A nonparametric ANOVA indicated that the group differences for the $48 \mathrm{~h}$ posttest were significant (Kruskal-Wallis test; $H=$ 20.4; $p<0.001)$. Furthermore, post hoc tests indicated that the 5-HT-treated group exhibited significantly more facilitation at $48 \mathrm{~h}$ than either the vehicletreated controls or the cocultures treated with chelerythrine after 5-HT (5-HT-Chel group). Chelerythrine treatment by itself did not affect the sensorimotor EPSP, as indicated by the lack of a significant difference between the EPSPs in cocultures treated with chelerythrine alone and those in the vehicle-treated control group. Finally, the disruptive effect of chelerythrine on the maintenance of LTF could not be accounted for by effects on neuronal input resistance or presynaptic spike threshold (Fig. 7C).

We attempted to reinstate LTF after chelerythrine treatment using brief 5-HT stimulation. There were four experimental groups used in the attempt. Three of the groups-Control $(n=11), 5$-HT $(n=$ $12)$, Chel $(n=10)$ - were treated identically with their counterparts in the previous experiment, except that the $1 \mathrm{~h}$ exposure to chelerythrine/vehicle solution started at $18 \mathrm{~h}$ after training with the 5-HT/vehicle solution, rather than at $24 \mathrm{~h}$ (Fig. $7 B$ ). Synapses in the fourth group (5-HT-ChelReinstate, $n=14$ ) were given the standard 5-HT training, followed by chelerythrine treatment at $18 \mathrm{~h}$; in addition, at $24 \mathrm{~h}$ this group was given a single, $5 \mathrm{~min}$ pulse of 5-HT $(100 \mu \mathrm{M})$, which, by itself, produces short-term, but not long-term, facilitation (Bartsch et al., 1995). The overall group differences for the $48 \mathrm{~h}$ posttest were significant (Kruskal-Wallis test; $H=15.1 ; p<0.002$ ). The LTF produced by 5 -HT treatment was disrupted by chelerythrine treatment at $18 \mathrm{~h}$. Furthermore, brief treatment with 5-HT at $24 \mathrm{~h}$ failed to reinstate the LTF in the chelerythrine-treated group. (See Fig. $7 D$ for the neuronal input resistances and presynaptic spike thresholds for this experiment.)
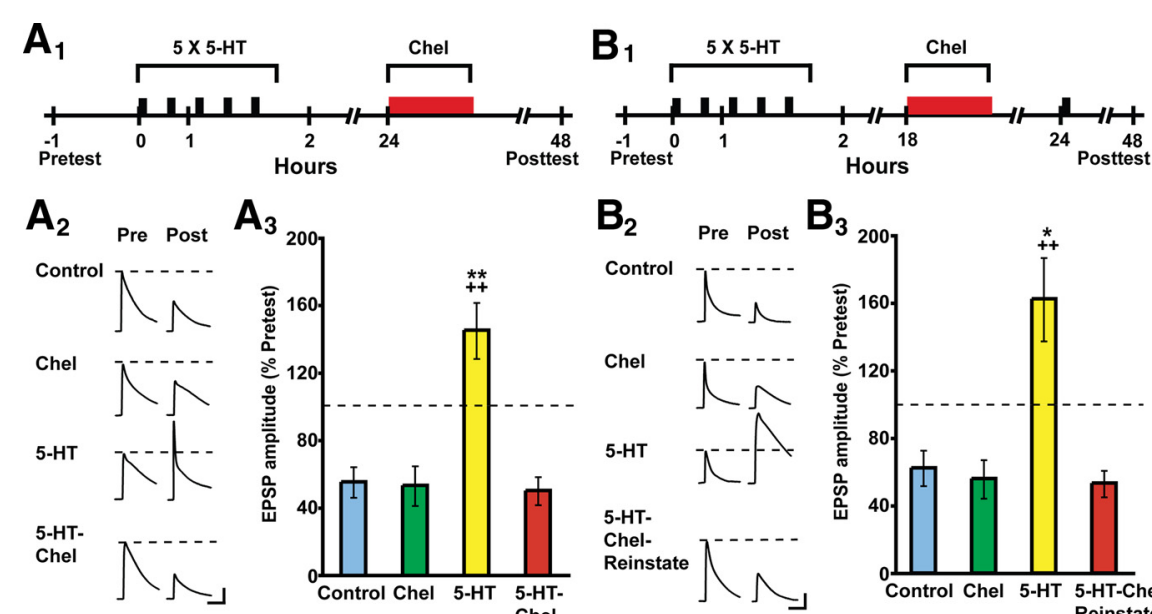

$\mathbf{A}_{3}$

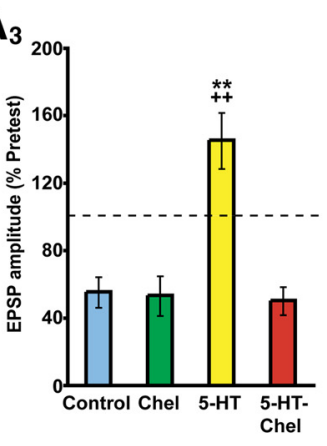

$\mathrm{B}_{2} \quad \mathrm{~B}_{3}$

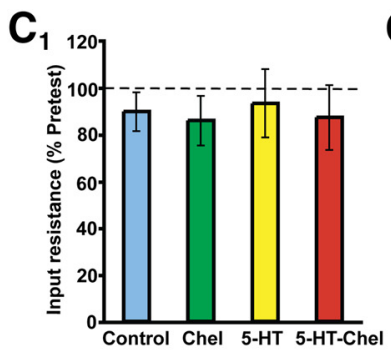

$\mathrm{C}_{2}{ }^{140}$
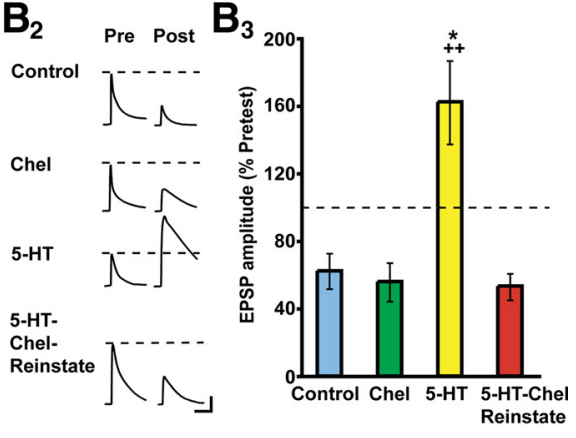

$\mathrm{C}_{3}$
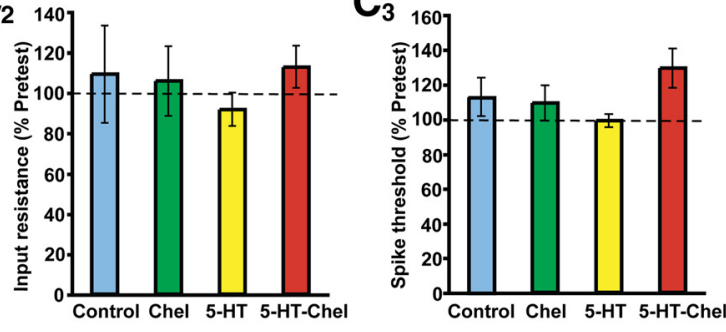

$D_{1}$
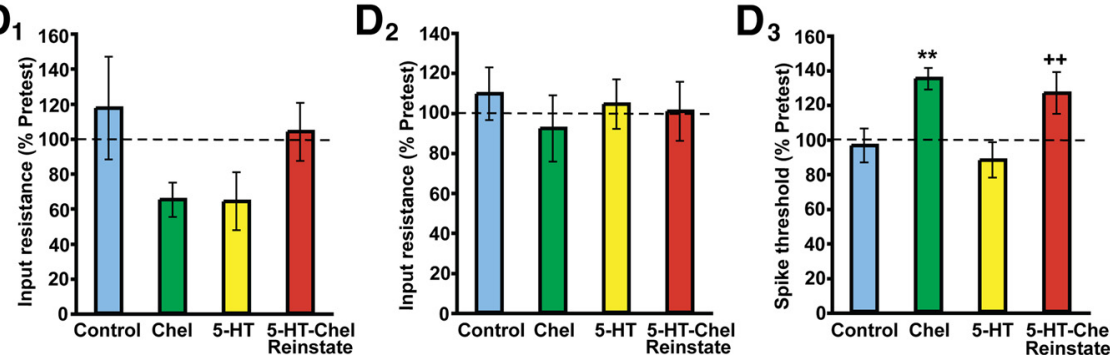

Figure 7. LTFdoes not exhibitreinstatement after disruption by chelerythrine. $A_{1}$, Experimental protocol. Twenty-four hours after 5-HT treatment, some cocultures were treated with 5-10 $\mu \mathrm{m}$ chelerythrine for $1 \mathrm{~h}$. Afterward, the drug was washed out with culture medium. $A_{2}$, Sample EPSPS. $A_{3}$, Effect of chelerythrine treatment at $24 \mathrm{~h}$ on the expression of $L T F$ at $48 \mathrm{~h}$. Four groups of cocultures were included in this experiment: one trained with $100 \mu \mathrm{m} 5$ - HT and then treated with the vehicle solution for $1 \mathrm{~h}$ at $24 \mathrm{~h}$ after 5 - $\mathrm{HT}$ training $(5-\mathrm{HT}$ group; $n=14)$; one that received only the vehicle solution during training and during the $1 \mathrm{~h}$ treatment $24 \mathrm{~h} \mathrm{later} \mathrm{(Control} \mathrm{group;} n=14$ ); one trained with 5 -HT and then treated with chelerythrine $(5-10 \mu \mathrm{m} ; 1 \mathrm{~h}) 24 \mathrm{~h}$ after training (5-HT-Chel group; $n=9)$; and, finally, a group trained with the vehicle solution and then treated with chelerythrine $24 \mathrm{~h}$ later (Chel; $n=10)$. Note that the synapses were not tested at $24 \mathrm{~h}$. SNK post hoc tests revealed that synapses that received the vehicle treatment after 5 - $\mathrm{HT}$ training were significantly facilitated at $48 \mathrm{~h}$ (5-HT group; normalized mean EPSP, $147 \pm 17 \%$ ), compared with synapses in the Control group [mean normalized EPSP, $56 \pm 9 \% ; Q=$ $19.5(p<0.01)$ ], and to synapses in the 5-HT-Chel group [mean normalized EPSP, $51 \pm 8 \% ; Q=19.6(p<0.01)$ ]. The EPSPs in the 5 -HT-Chel group did not differ significantly from those in the Chel group (mean normalized EPSP, $54 \pm 12 \%$ ). Also, the EPSPs in the Control and Chel groups did not differ significantly, indicating that chelerythrine treatment alone did not affect the synaptic responses in cocultures not trained with 5-HT. Asterisks, Comparison between the 5-HT and Control data; plus signs, comparison between the 5-HT and 5-HT-Chel data. $\boldsymbol{B}_{1}$, Experimental protocol used to attempt to reinstate LTF. One hour $5-10 \mu \mathrm{m}$ chelerythrine treatment was given to some cocultures at $18 \mathrm{~h}$ after 5 - HT training. At $24 \mathrm{~h}$, one extra 5 min pulse of 5 -HT (black bar) was applied to cocultures in the 5 - $\mathrm{HT}$-Chel-Reinstate group. $\boldsymbol{B}_{2 \text {, }}$ Sample EPSPS. $\boldsymbol{B}_{3}$, Retraining with one 5 min pulse of 5 -HT, which produces short-term synaptic facilitation, did not reinstate LTF after its disruption by chelerythrine. The mean normalized EPSP in the 5 -HT group (161 $\pm 25 \%)$ was significantly facilitated compared with that in the Control group $[62 \pm 11 \%, Q=15.4(p<0.05)]$ and the 5 -HT-Chel-Reinstate group $[53 \pm 8 \%, Q=18.6(p<0.01)]$. The difference between the mean normalized EPSPs in the Chel $(56 \pm 11 \%)$ and the 5 -HT-Chel-Reinstate groups were not significant, nor was that between the Control and Chel groups. Asterisks, Comparison between the 5-HT and Control data; plus signs, comparison between the 5-HT and 5-HT-Chel-Reinstate data. $C_{1}$, The mean input resistance of the sensory neurons did not change significantly in the experiments shown in $A . C_{2}$, There was also no significant change in the mean input resistance of the motor neurons in these experiments (same cocultures as in $\left.C_{7}\right) \cdot C_{3}$, Chelerythrine treatment did not significantly affect the mean spike threshold of the sensory neurons (experiments shown in $A$ ). $\boldsymbol{D}_{1}$, No significant changes were observed in the mean input resistance of the sensory neurons in the experiments of $\boldsymbol{B}$. $\boldsymbol{D}_{2}$, Neither did any significant changes occur in the mean input resistance of the motor neurons in these experiments (same cocultures as in $\boldsymbol{D}_{\mathbf{1}}$ ). $\boldsymbol{D}_{\mathbf{3}}$, The sensory neuron spike threshold increased significantly in the chelerythrine-treated cocultures in the experiments of $\boldsymbol{B}$. However, the synaptic change observed in this experiment cannot be attributed to the effect of this drug on presynaptic spike threshold because the increase occurred in both the untrained and $5-\mathrm{HT}$-trained cocultures exposed to chelerythrine. Asterisks, Comparison between the 5-HT and Chel groups; plus signs, comparison between the 5-HT and 5-HT-Chel-Reinstate groups. 


\section{Discussion}

\section{Activity of PKM Apl III maintains long-term memory in Aplysia}

We found that inhibition of PKM Apl III, using either ZIP or a low concentration of chelerythrine, erases both LTS and LTF in Aplysia. After treatment with ZIP or chelerythrine, we did not observe spontaneous recovery of the long-term behavioral and synaptic changes; furthermore, the long-term changes could not be reinstated by stimulation that normally produces short-term sensitization/facilitation. One might question the specificity of our inhibitory treatments for PKM Apl III. However, ZIP mimics the pseudosubstrate of the regulatory domain of $\mathrm{PKC} \zeta$, and, as pointed out previously, this pseudosubstrate sequence is conserved in PKC Apl III (Bougie et al., 2009). Furthermore, we found no inhibitory effect of the scrambled ZIP peptide in control behavioral and synaptic experiments. Finally, we have previously shown in biochemical assays that a low concentration of chelerythrine, like that used in the present experiments, is specific for PKM Apl III. In particular, at concentrations $<20 \mu \mathrm{M}$, chelerythrine does not inhibit classical and novel PKCs in Aplysia (Villareal et al., 2009). Therefore, we do not believe that our results can be attributed to nonspecific actions of the inhibitors.

One caveat concerning our results is that we do not know the extent to which the behavioral effects of the PKM inhibitors were attributable to direct actions on siphon sensorimotor synapses in the intact animal. Because the drugs were introduced via intrahemocoel injections, both ZIP and chelerythrine had access to the entire Aplysia CNS. Therefore, although facilitation of sensorimotor synapses in the abdominal ganglion has been demonstrated to mediate sensitization of the SWR (Antonov et al., 1999), and although we have shown here that inhibition of PKM Apl III disrupts maintenance of both LTS in vivo and LTF of the sensorimotor synapse in vitro, we cannot rule out the possibility that our behavioral results were attributable, at least in part, to actions of ZIP and chelerythrine on central sites other than the siphon sensorimotor synapse.

The present results add to the accumulating evidence that PKMs play crucial roles in the persistence of long-term memory and long-term synaptic plasticity in both vertebrates and invertebrates (Drier et al., 2002; Ling et al., 2002; Pastalkova et al., 2006; Shema et al., 2007; Serrano et al., 2008). Whether the maintenance of other forms of long-term memory in Aplysia, such as long-term habituation (Carew et al., 1972; Ezzeddine and Glanzman, 2003) and classical conditioning (Carew et al., 1981), also depends on PKM Apl III activity remains to be determined. Notice, however, that not all forms of vertebrate memory require PKM $\zeta$ activity for their maintenance (Shema et al., 2007).

\section{Relative roles of PKM Apl III and ApCPEB in memory maintenance in Aplysia}

Previous studies using the in vitro sensorimotor synapse have provided support for the idea that ongoing local protein synthesis, regulated by a prion-like protein, ApCPEB, mediates an early phase ( $\leq 48 \mathrm{~h}$ ) of the maintenance of long-term memory in Aplysia (Si et al., 2003a,b, 2010; Miniaci et al., 2008). Our finding that temporary disruption of protein synthesis with anisomycin did not disrupt the 7-d-old memory for LTS in intact animals is consistent with this idea. Moreover, there are theoretical reasons for supposing that the role of ApCPEB in maintaining LTS is limited to an early stage. Vertebrate studies have consistently found that, without a reminder stimulus to trigger memory reconsolidation (Nader et al., 2000b), temporary inhibition of pro- tein synthesis does not disrupt well consolidated memories (Davis and Squire, 1984).

We found that treatment with either ZIP or chelerythrine at $24 \mathrm{~h}$ after 5-HT training disrupts the expression of LTF of the sensorimotor synapse $24 \mathrm{~h}$ later. Interestingly, the same result is obtained when the action of ApCPEB is inhibited at $24 \mathrm{~h}$, whether by treatment with an inhibitor of protein synthesis, an ApCPEB antisense oligonucleotide, or an antibody that preferentially binds the multimeric form of ApCPEB (Si et al., 2003b, 2010; Miniaci et al., 2008). Thus, these two memory-maintaining processes may overlap temporally. If so, it will be interesting to determine whether these processes interact and, if they do interact, how.

Although our anisomycin results are consistent with the idea that ApCPEB does not mediate late-stage memory maintenance in Aplysia, the results must nonetheless be regarded with some caution. This is because it is possible that ApCPEB has actions at synaptic sites that support long-term memory that are distinct from the regulation of local protein synthesis. Furthermore, recent computational models bring into question the results of classical tests of the role of protein synthesis in memory consolidation. These models indicate that, in those cases in which the underlying mechanism of consolidation involves a molecular positive-feedback loop-as is likely to be the case with PKM (see below) - beyond 40 min after training, protein synthesis must be inhibited by $>95 \%$ to actually disrupt memory stabilization (Zhang et al., 2010). A recent estimate of the efficacy of anisomycin in the molluscan CNS indicates that it blocks protein synthesis by $\geq 81 \%$ for $3 \mathrm{~h}$ and is completely ineffective by $12 \mathrm{~h}$ after treatment (Fulton et al., 2005). Thus, if ApCPEB is also part of a positive-feedback loop that maintains synaptic facilitation in Aplysia, it is possible that our anisomycin injections, which were made $7 \mathrm{~d}$ after training, were ineffective in disrupting the actions of ApCPEB.

\section{How does PKM Apl III activity maintain long-term memory in Aplysia?}

An important question to be addressed by future studies is how PKM Apl III maintains LTS and LTF in Aplysia. Note that, at present, the mechanism whereby $\mathrm{PKM} \zeta$ maintains long-term memory in mammals is poorly understood. In particular, it is unclear why the temporary disruption of PKM $\zeta$ activity by ZIP can erase memories in rodents (Pastalkova et al., 2006; Shema et al., 2007). One might expect that after the peptide is no longer present-because of either diffusion or degradation-the disrupted memories would reappear. Sacktor (2011) has hypothesized that $\mathrm{PKM} \zeta$ activity at potentiated synapses is maintained by a positive-feedback loop involving the trafficking of GluR2 subunit-containing AMPA receptors to potentiated synapses. [It is the delivery of additional AMPA receptors to the postsynaptic membrane that represents the molecular engram in most current models of LTP (Blair et al., 2001; Morris et al., 2003; Roberts and Glanzman, 2003).] According to Sacktor's model, PKM $\zeta$ dependent phosphorylation of GluR2, or of an accessory protein, causes the AMPA receptor subunit to be trafficked to the postsynaptic membrane, where it forms a "synaptic tag"; the presence of $\mathrm{PKM} \zeta$ at the synapse, in turn, is maintained by its association with GluR2. ZIP, by inhibiting $\mathrm{PKM} \zeta$, breaks this positivefeedback loop by blocking the ongoing phosphorylation of GluR2 (or the accessory protein), which results in the endocytosis of the AMPA receptor subunit; in the absence of the synaptic tag, $\mathrm{PKM} \zeta$ is removed from the synaptic region, and cannot restart the transport of GluR2 subunits to the formerly potentiated syn- 
apse once ZIP is eliminated. Consequently, the synapses are reset to their naive state.

It is unclear whether such a scheme can account for memory maintenance and erasure in Aplysia. Sacktor's model is consistent with our finding (Fig. $5 B$ ) that the temporary inhibition of protein synthesis by anisomycin does not disrupt established longterm memory in Aplysia (but see above). It should be pointed out, however, that there is at least one major difference between the Aplysia and mammalian PKM isoforms. PKM Apl III is not formed, as $\mathrm{PKM} \zeta$ is (Hernandez et al., 2003), by transcription from an alternative start site within the atypical PKC, PKC Apl III, gene; rather, as stated previously, PKM Apl III is produced by calpain-dependent cleavage of PKC Apl III (Bougie et al., 2009). Despite this difference, long-term synaptic plasticity and memory in Aplysia may well be maintained by a positive-feedback loop involving continual PKM Apl III-dependent protein phosphorylation, as Sacktor believes to be true for mammalian LTP and long-term memory.

What are the downstream cellular consequences of continued PKM Apl III activity that serve to maintain stable synaptic facilitation in Aplysia? One possibility is that ongoing PKM Apl III activity maintains learning-induced changes in neuronal structure (Liu et al., 2009). Both LTS and LTF are accompanied by the growth of new synapses, and this growth involves both presynaptic and postsynaptic structural changes (Bailey and Chen, 1983, 1988a,b; Glanzman et al., 1990; Wainwright et al., 2002). If maintenance of these learning-related, long-term structural changes depends on PKM Apl III, treatment with ZIP or chelerythrine would be expected to reverse them. Another way in which PKM Apl III activity may mediate the persistence of LTS in Aplysia is through enhancement of the trafficking of glutamate receptors at facilitated synapses. Migues et al. (2010) have provided evidence that $\mathrm{PKM} \zeta$ activity in the rat amygdala maintains the memory for conditioned fear by regulating the trafficking of postsynaptic GluR-2 AMPA receptor subunits (above). Modulation of AMPAtype receptor trafficking appears to play a critical role in synaptic plasticity and learning in Aplysia (Zhu et al., 1997; Chitwood et al., 2001; Li et al., 2005; Li et al., 2009; Glanzman, 2010), as it does in mammals (Kessels and Malinow, 2009). Possibly, PKM Apl III activity maintains an increased number of AMPA-type receptors at postsynaptic sites after training that induces LTS. In support of the idea that PKM Apl III is involved in AMPA receptor trafficking in Aplysia, we recently found that chelerythrine treatment reverses the increased expression of glutamate receptors in the Aplysia CNS that characterizes LTS (Chen et al., 2008) (S. Chen, K. Pearce, D. Cai, and D. L. Glanzman, unpublished data).

\section{Conclusion}

We have demonstrated that inhibiting an isoform of PKM eliminates the long-term memory for a form of nonassociative learning, as well as the specific form of long-term synaptic plasticity that underlies the learning, in the well studied invertebrate Aplysia. The demonstration of memory erasure in this relatively simple model system should greatly facilitate a reductionistic analysis of how the activity of PKM supports the persistence of memory. Moreover, given the evidence that ApCPEB also plays a role in the persistence of long-term memory in Aplysia (Si et al., 2003b, 2010; Miniaci et al., 2008), we are now in a position to study, potentially, how these two mechanisms interact to maintain long-term memory.

\section{References}

Abbott NJ, Lane NJ, Bundgaard M (1986) The blood-brain interface in invertebrates. Ann N Y Acad Sci 481:20-42.
Agranoff BW, Klinger PD (1964) Puromycin effect on memory fixation in the goldfish. Science 146:952-953.

Alarcon JM, Hodgman R, Theis M, Huang YS, Kandel ER, Richter JD (2004) Selective modulation of some forms of Schaffer collateral-CA1 synaptic plasticity in mice with a disruption of the CPEB-1 gene. Learn Mem 11:318-327.

Antonov I, Kandel ER, Hawkins RD (1999) The contribution of facilitation of monosynaptic PSPs to dishabituation and sensitization of the Aplysia siphon withdrawal reflex. J Neurosci 19:10438-10450.

Bailey CH, Chen M (1983) Morphological basis of long-term habituation and sensitization in Aplysia. Science 220:91-93.

Bailey CH, Chen M (1988a) Long-term memory in Aplysia modulates the total number of varicosities of single identified sensory neurons. Proc Natl Acad Sci U S A 85:2373-2377.

Bailey CH, Chen M (1988b) Long-term sensitization in Aplysia increases the number of presynaptic contacts onto the identified gill motor neuron L7. Proc Natl Acad Sci U S A 85:9356-9359.

Bartsch D, Ghirardi M, Skehel PA, Karl KA, Herder SP, Chen M, Bailey CH, Kandel ER (1995) Aplysia CREB2 represses long-term facilitation: relief of repression converts transient facilitation into long-term functional and structural change. Cell 83:979-992.

Blair HT, Schafe GE, Bauer EP, Rodrigues SM, LeDoux JE (2001) Synaptic plasticity in the lateral amygdala: a cellular hypothesis of fear conditioning. Learn Mem 8:229-242.

Bougie JK, Lim T, Farah CA, Manjunath V, Nagakura I, Ferraro GB, Sossin WS (2009) The atypical protein kinase C in Aplysia can form a protein kinase M by cleavage. J Neurochem 109:1129-1143.

Cai D, Chen S, Glanzman DL (2008) Postsynaptic regulation of long-term facilitation in Aplysia. Curr Biol 18:920-925.

Carew TJ, Pinsker HM, Kandel ER (1972) Long-term habituation of a defensive withdrawal reflex in Aplysia. Science 175:451-454.

Carew TJ, Walters ET, Kandel ER (1981) Classical conditioning in a simple withdrawal reflex in Aplysia californica. J Neurosci 1:1426-1437.

Castellucci VF, Blumenfeld H, Goelet P, Kandel ER (1989) Inhibitor of protein synthesis blocks long-term behavioral sensitization in the isolated gill-withdrawal reflex of Aplysia. J Neurobiol 20:1-9.

Chen S, Fulton D, Rivera E, Glanzman DL (2008) Changes in glutamate receptor mRNA levels during sensitization of Aplysia californica. Soc Neurosci Abstr 34:880.821.

Chitwood RA, Li Q, Glanzman DL (2001) Serotonin facilitates AMPA-type responses in isolated siphon motor neurons of Aplysia in culture. J Physiol 534:501-510.

Dash PK, Hochner B, Kandel ER (1990) Injection of the cAMP-responsive element into the nucleus of Aplysia sensory neurons blocks long-term facilitation. Nature 345:718-721.

Davis HP, Squire LR (1984) Protein synthesis and memory: a review. Psychol Bull 96:518-559.

Drier EA, Tello MK, Cowan M, Wu P, Blace N, Sacktor TC, Yin JC (2002) Memory enhancement and formation by atypical PKM activity in Drosophila melanogaster. Nat Neurosci 5:316-324.

Ezzeddine Y, Glanzman DL (2003) Prolonged habituation of the gillwithdrawal reflex in Aplysia depends on protein synthesis, protein phosphatase activity, and postsynaptic glutamate receptors. J Neurosci 23:9585-9594.

Frost WN, Castellucci VF, Hawkins RD, Kandel ER (1985) Monosynaptic connections made by the sensory neurons of the gill- and siphonwithdrawal reflex in Aplysia participate in the storage of long-term memory for sensitization. Proc Natl Acad Sci U S A 82:8266-8269.

Fulton D, Kemenes I, Andrew RJ, Benjamin PR (2005) A single timewindow for protein synthesis-dependent long-term memory formation after one-trial appetitive conditioning. Eur J Neurosci 21:1347-1358.

Fulton D, Condro MC, Pearce K, Glanzman DL (2008) The potential role of postsynaptic phospholipase $\mathrm{C}$ activity in synaptic facilitation and behavioral sensitization in Aplysia. J Neurophysiol 100:108-116.

Furgal SM, Brownell PH (1987) Ganglionic circulation and its effects on neurons controlling cardiovascular functions in Aplysia californica. J Exp Zool 244:347-363.

Glanzman DL (2010) Common mechanisms of synaptic plasticity in vertebrates and invertebrates. Curr Biol 20:R31-R36.

Glanzman DL, Kandel ER, Schacher S (1990) Target-dependent structural changes accompanying long-term synaptic facilitation in Aplysia neurons. Science 249:799-802. 
Goelet P, Castellucci VF, Schacher S, Kandel ER (1986) The long and the short of long-term memory—a molecular framework. Nature 322:419-422.

Hernandez AI, Blace N, Crary JF, Serrano PA, Leitges M, Libien JM, Weinstein G, Tcherapanov A, Sacktor TC (2003) Protein kinase M $\zeta$ synthesis from a brain mRNA encoding an independent protein kinase $\mathrm{C} \zeta$ catalytic domain. Implications for the molecular mechanism of memory. J Biol Chem 278:40305-40316.

Keleman K, Krüttner S, Alenius M, Dickson BJ (2007) Function of the Drosophila CPEB protein Orb2 in long-term courtship memory. Nat Neurosci 10:1587-1593.

Kessels HW, Malinow R (2009) Synaptic AMPA receptor plasticity and behavior. Neuron 61:340-350.

Li HL, Huang BS, Vishwasrao H, Sutedja N, Chen W, Jin I, Hawkins RD, Bailey CH, Kandel ER (2009) Dscam mediates remodeling of glutamate receptors in Aplysia during de novo and learning-related synapse formation. Neuron 61:527-540.

Li Q, Roberts AC, Glanzman DL (2005) Synaptic facilitation and behavioral dishabituation in Aplysia: dependence upon release of $\mathrm{Ca}^{2+}$ from postsynaptic intracellular stores, postsynaptic exocytosis and modulation of postsynaptic AMPA receptor efficacy. J Neurosci 25:5623-5637.

Lin XY, Glanzman DL (1994) Long-term potentiation of Aplysia sensorimotor synapses in cell culture: regulation by postsynaptic voltage. Proc Biol Sci 255:113-118.

Ling DS, Benardo LS, Serrano PA, Blace N, Kelly MT, Crary JF, Sacktor TC (2002) Protein kinase $M \zeta$ is necessary and sufficient for LTP maintenance. Nat Neurosci 5:295-296.

Liu XF, Tari PK, Haas K (2009) PKM $\zeta$ restricts dendritic arbor growth by filopodial and branch stabilization within the intact and awake developing brain. J Neurosci 29:12229-12235.

McGaugh JL (1966) Time-dependent processes in memory storage. Science 153:1351-1358.

McGaugh JL (2000) Memory-a century of consolidation. Science 287:248-251.

Migues PV, Hardt O, Wu DC, Gamache K, Sacktor TC, Wang YT, Nader K (2010) $\mathrm{PKM} \zeta$ maintains memories by regulating GluR2-dependent AMPA receptor trafficking. Nat Neurosci 13:630-634.

Miniaci MC, Kim JH, Puthanveettil SV, Si K, Zhu H, Kandel ER, Bailey CH (2008) Sustained CPEB-dependent local protein synthesis is required to stabilize synaptic growth for persistence of long-term facilitation in Aplysia. Neuron 59:1024-1036.

Montarolo PG, Goelet P, Castellucci VF, Morgan J, Kandel ER, Schacher S (1986) A critical period for macromolecular synthesis in long-term heterosynaptic facilitation in Aplysia. Science 234:1249-1254.

Morris RG, Moser EI, Riedel G, Martin SJ, Sandin J, Day M, O'Carroll C (2003) Elements of a neurobiological theory of the hippocampus: the role of activity-dependent synaptic plasticity in memory. Philos Trans $\mathrm{R}$ Soc Lond B Biol Sci 358:773-786.

Müller GE, Pilzecker A (1900) Experimentelle Beiträge zur Lehre vom Gedächtnis. Z Psychol 1:1-300.
Nader K, Schafe GE, Le Doux JE (2000a) Fear memories require protein synthesis in the amygdala for reconsolidation after retrieval. Nature 406:722-726.

Nader K, Schafe GE, LeDoux JE (2000b) The labile nature of consolidation theory. Nat Rev Neurosci 1:216-219.

Pastalkova E, Serrano P, Pinkhasova D, Wallace E, Fenton AA, Sacktor TC (2006) Storage of spatial information by the maintenance mechanism of LTP. Science 313:1141-1144.

Pinsker HM, Hening WA, Carew TJ, Kandel ER (1973) Long-term sensitization of a defensive withdrawal reflex in Aplysia. Science 182:1039-1042.

Rescorla RA, Heth CD (1975) Reinstatement of fear to an extinguished conditioned stimulus. J Exp Psychol Anim Behav Process 1:88-96.

Roberts AC, Glanzman DL (2003) Learning in Aplysia: looking at synaptic plasticity from both sides. Trends Neurosci 26:662-670.

Sacktor TC (2011) How does PKM $\zeta$ maintain long-term memory? Nat Rev Neurosci 12:9-15.

Sara SJ (2000) Retrieval and reconsolidation: toward a neurobiology of remembering. Learn Mem 7:73-84.

Serrano P, Friedman EL, Kenney J, Taubenfeld SM, Zimmerman JM, Hanna J, Alberini C, Kelley AE, Maren S, Rudy JW, Yin JC, Sacktor TC, Fenton AA (2008) PKM $\zeta$ maintains spatial, instrumental, and classically conditioned long-term memories. PLoS Biol 6:2698-2706.

Shema R, Sacktor TC, Dudai Y (2007) Rapid erasure of long-term memory associations in the cortex by an inhibitor of PKM $\zeta$. Science 317:951-953.

Si K, Lindquist S, Kandel ER (2003a) A neuronal isoform of the Aplysia CPEB has prion-like properties. Cell 115:879-891.

Si K, Giustetto M, Etkin A, Hsu R, Janisiewicz AM, Miniaci MC, Kim JH, Zhu $\mathrm{H}$, Kandel ER (2003b) A neuronal isoform of CPEB regulates local protein synthesis and stabilizes synapse-specific long-term facilitation in $A p$ lysia. Cell 115:893-904.

Si K, Choi YB, White-Grindley E, Majumdar A, Kandel ER (2010) Aplysia $\mathrm{CPEB}$ can form prion-like multimers in sensory neurons that contribute to long-term facilitation. Cell 140:421-435.

Villareal G, Li Q, Cai D, Fink AE, Lim T, Bougie JK, Sossin WS, Glanzman DL (2009) Role of protein kinase $\mathrm{C}$ in the induction and maintenance of serotonin-dependent enhancement of the glutamate response in isolated siphon motor neurons of Aplysia californica. J Neurosci 29:5100-5107.

von Kraus LM, Sacktor TC, Francis JT (2010) Erasing sensorimotor memories via PKMzeta inhibition. PLoS ONE 5:e11125.

Wainwright ML, Zhang H, Byrne JH, Cleary LJ (2002) Localized neuronal outgrowth induced by long-term sensitization training in Aplysia. J Neurosci 22:4132-4141.

Zhang Y, Smolen P, Baxter DA, Byrne JH (2010) The sensitivity of memory consolidation and reconsolidation to inhibitors of protein synthesis and kinases: computational analysis. Learn Mem 17:428-439.

Zhu H, Wu F, Schacher S (1997) Site-specific and sensory neurondependent increases in postsynaptic glutamate sensitivity accompany serotonin-induced long-term facilitation at Aplysia sensorimotor synapses. J Neurosci 17:4976-4986. 